\title{
¿Ciencias malditas? Asiriología y Egiptología: metáforas coloniales, objetos y museos desde Sudamérica
}

Cursed sciences? Assyriology and Egyptology: colonial metaphors, objects, and museums from South America

https://doi.org/10.1590/1982-0267202 1v29e49

\section{LEILA SALEM ${ }^{\top}$}

https://orcid.org/0000-0002-7339-9636

Universidad Nacional de La Plata / Buenos Aires, Argentina

\section{RODRIGO CABRERA ${ }^{2}$}

https://orcid.org/0000-0002-7299-6068

Universidad de Buenos Aires / Buenos Aires, Argentina

RESUMEN: En el presente trabajo, se discute cómo la construcción de metáforas coloniales desde mediados del siglo XIX en Occidente favoreció la cimentación del nuevo orden imperialista que promovió la dominación política y económica de Asia y África, y, asimismo, el expolio de los objetos culturales pertenecientes a las sociedades nativas. Las metáforas coloniales no sólo tuvieron aceptación entre los miembros de la clase dominante, sino también entre quienes pertenecían a la intelectualidad del momento, sobre todo a partir de la gestación de los llamados Estudios del Próximo Oriente antiguo. Por otra parte, producto de la confiscación de los objetos culturales de las regiones sometidas, se conformaron los museos europeos y norteamericanos, cuyo modelo coleccionista fue emulado por las elites de Sudamérica.

PALABRAS CLAVE: Metáforas coloniales. Museos. Asiriología. Egiptología. 
Historia Antigua I (Oriente) en la misma casa de estudios. Becario doctoral del Consejo Nacional de Investigaciones Científicas y Técnicas (Conicet, Argentina) con lugar de trabajo en el Instituto Multidisciplinario de Historia y Ciencias $\mathrm{Hu}-$ manas (IMHICIHU, Conicet). Miembro del Grupo de Lenguas y Escrituras de Oriente (Geleo, Argentina). E-mail:<cabrera.pertusatti@ gmail.com>.
ABSTRACT: This paper discusses how the construction of colonial metaphors from the mid-19 $9^{\text {th }}$ century in the Western world favored the foundation of the new imperialist order that promoted the political and economic domination of Asia and Africa and the looting of the cultural property of native peoples. These metaphors were embraced not only by members of the ruling class, but also by those belonging to the intelligentsia of the time, especially from the gestation of the so-called Ancient Near Eastern Studies. The confiscation of cultural objects from subject regions grounded the formation of the European and North American museums, whose collector model was emulated by the elites of South America.

KEYWORDS: Colonial metaphors. Museums. Assyriology. Egyptology. 
PUNTO DE PARTIDA: EL ORIENTALISMO Y LAS METÁFORAS COLONIALES

Como punto de partida, decidimos comenzar con la pregunta "¿qué es el Orientalismo?" a partir de una revisión epistemológica, ya que a través de la misma interpelación se establece una dimensión de sentidos comunes habilitados a partir de "metáforas coloniales" sostenidas por siglos de dominación y, por tanto, por procesos de alienación operados desde Europa. Tal vez, por medio de una presunción gnoseológica inocente, la indagación sobre esa alteridad se pensaría despojada de prejuicios y, más bien, centrada en una racionalidad aséptica. Sin embargo, todo proceso de construcción de conocimiento es también una modalidad de cimentación de poder perpetrado por "metáforas", las cuales no sólo están insertas en la vida cotidiana sino también en ese saber hegemónico y civilizador como es la ciencia occidental. Tal como plantean George Lakoff y Mark Johnson,

[p]ara la mayoría de la gente, la metáfora es un recurso de la imaginación poética, y los ademanes retóricos, una cuestión de lenguaje extraordinario más que ordinario. Es más, la metáfora se contempla característicamente como un rasgo sólo del lenguaje, cosa de palabras más que de pensamiento o acción. Por esta razón, la mayoría de la gente piensa que pueden arreglárselas perfectamente sin metáforas. Nosotros hemos llegado a la conclusión de que la metáfora, por el contrario, impregna la vida cotidiana, no solamente el lenguaje, sino también el pensamiento y la acción. Nuestro sistema conceptual ordinario, en términos del cual pensamos y actuamos, es fundamentalmente de naturaleza metafórica. ${ }^{3}$

De este modo, lo cotidiano es un palimpsesto de metáforas al igual que el lenguaje poético o la ciencia, pero esta última dominada por criterios de verdad a partir de una lógica abstracta pensada como universal. Ante este punto, los discursos científicos y sus metáforas están vinculados a puntos de reflexión específicos sobre la alteridad oriental que responden a necesidades particulares e históricas sobre la estructuración de la subjetividad europea a mediados del siglo XIX. Sin embargo, aunque la construcción de un sujeto europeo comenzaría a materializarse en el siglo XIX, hay indicios para rastrear ese proceso en la Antigüedad clásica, a partir de la obra de Heródoto, en la que el modelo de orden griego se opondría a la "barbarie" de los persas. ${ }^{4}$

El ser-en-el-mundo decimonónico era un sujeto burgués, heteropatriarcal y, fundamentalmente, europeo. De este modo, ser europeo en el siglo XIX significaba también identificarse con una supra-presencia dominante que se vindicaba a partir de una metáfora colonial y ejercía una autoridad por encima de una subalternidad compuesta por objetos culturales antiguos -ahora artefactos museológicos- de
3. Lakoff y Johnson (1980, p. 39).

4. Cf. Hartog (1980). 
5. Bernal (1987). Enrique Dussel señala que se produjo, con el modelo romántico alemán de fines del siglo XVIII, una "diacronía unilineal" entre Grecia-Roma-Europa, en la que la antigua región de la Hélade fue el modelo de lo civilizado, lo político y lo humano (Dussel, 2004). En relación al "modelo ario", podemos mencionar algunas críticas, contenidas, por ejemplo, en Bernal (2001). Puntualmente, en conexión con la postura "afrocentrista" de Bernal, cf. Lefkowitz (1996), Marchand y Grafton (1997), Schmitz (1999) y Colla (2007).

6. Kristeva (1980, p. 9).

7. Ibid., p. 12. "civilizaciones exóticas y arcaicas" y/o por una gama diversa de "pueblos salvajes". En ese contexto, el silenciamiento de esa alteridad implicó lo que Martin Bernal denominó "modelo ario", 5 a partir del cual todo vestigio y/o préstamo sociocultural presente en el mundo griego proveniente de Asia, y sobre todo de África, fue borrado con el sostén de la intelectualidad de fines del siglo XIX-cuya premisa tuvo vigencia hasta mediados del siglo XX. De este modo, el fenómeno cultural griego sería un producto endógeno del universo indoeuropeo, de donde retomaba sus rasgos de civilidad y armonía en relación a la Filosofía y las Artes.

Así, a mediados del siglo XIX, cuando las Ciencias Sociales y Humanas delimitaban sus respectivos campos de estudio $y$, en paralelo, las emergentes naciones europeas también proclamaban sus prototipos socioculturales afines e inventaban sus propias tradiciones o folklores, se dio un contexto de abyección contingente y definición de una otredad no europea a través del imperialismo y el respectivo proceso neocolonial. Europa se inventó a sí misma a partir de un juego de metáforas coloniales y por medio de la abyección como herramienta para su constitución identitaria. De acuerdo a Julia Kristeva, la "abyección" es un dispositivo psicológico/antropológico/semiológico que podría ser entendido como una contraimagen del ego en una modalidad psicoanalítica. ${ }^{6}$ Por lo tanto, lo abyecto, en el contexto señalado, son esas subalternidades negadas y subyugadas a la hegemonía europea. Siguiendo la discusión planteada por la autora:

[n]o es por lo tanto la ausencia de limpieza o de salud lo que vuelve abyecto, sino aquello que perturba una identidad, un sistema, un orden. Aquello que no respeta los límites, los lugares, las reglas. La complicidad, lo ambiguo, lo mixto. El traidor, el mentiroso, el criminal con la conciencia limpia, el violador desvergonzado, el asesino que pretende salvar [...] Todo crimen, porque señala la fragilidad de la ley, es abyecto, pero el crimen premeditado, la muerte solapada, la venganza hipócrita lo son aun más porque aumentan esta exhibición de la fragilidad legal. Aquel que rechaza la moral no es abyecto -puede haber grandeza amoral y aun en un crimen que hace ostentación de su falta de respeto de la ley, rebelde, libertador y suicida. La abyección es inmoral, tenebrosa, amiga de rodeos, turbia: un terror que disimula, un odio que sonríe, una pasión por un cuerpo cuando lo comercio en lugar de abrazarlo, un deudor que estafa, un amigo que nos clava un puñal por la espalda.?

En suma, si volvemos a la pregunta del comienzo de este apartado, "¿qué es el Orientalismo?", la misma puede ser discutida en relación a las metáforas coloniales que se dieron en Europa a mediados del siglo XIX, en el momento en el que Asia y África fueron incorporadas formalmente como territorios bajo dominación europea, mientras Latinoamérica se convertía en la productora de materias primas en el contexto de la división internacional del trabajo. 
Asimismo, si bien el Orientalismo se presentó, en ese momento, como parte de un proceso de encuentro y colonización de Asia y África por Europa y la invención de un lugar -Oriente- como antítesis de la civilización y la racionalidad occidental, y depositario también de metáforas coloniales, implicó además el puntapié para los desarrollos disciplinares abocados a los estudios de los pueblos que habitaron el occidente de Asia y el norte de África: la Asiriología y la Egiptología.

La primera se conformó como una disciplina filológica centrada en los estudios de la Mesopotamia. En un principio, se hizo foco en Asiria -y de ahí del nombre Asiriología-, pero el desarrollo del conocimiento de las lenguas antiguas que emplearon el sistema de escritura cuneiforme se amplió a otras sociedades incluidas en la región: los sumerios y los babilonios, en un primer momento, a los que se sumaron los hurritas, los hititas y los persas. De hecho, se los describía bajo criterios "raciales" y no como grupos lingüísticos, si bien ya se había delimitado que el sumerio, por ejemplo, no era parte de las lenguas semíticas. En cuanto a la revisión epistemológica-historiográfica del uso del concepto de "Mesopotamia" en el ámbito asiriológico para analizar el pasado de Iraq, sólo algunas/os autoras/ es han problematizado la cuestión. A propósito, el vocablo "Mesopotamia" constituye un constructo helenocéntrico y que sirvió para designar una realidad sociohistórica heterogénea, a la manera de una instancia anterior a la civilización occidental. A pesar de ello, si bien algunas/os especialistas emplean el concepto de "antiguo Iraq" para referirse al contexto previo a la dominación macedonia de la región, son escasas las discusiones que articulan y repiensan de qué manera los procesos actuales y ciertas prácticas sociales pueden ser "reensambladas", por medio de una necesaria revisión epistemológica, con el pasado. ${ }^{8}$

En el caso de la Egiptología, el problema de la relación con las sociedades modernas no aconteció de la misma forma, ya que el concepto disciplinar mismo, a mediados del siglo XIX, se definió para significar únicamente el estudio del antiguo Egipto. De esta manera, se despreciaba y rechazaba la historia del Egipto islámico y moderno, dando cuenta de la primacía que los occidentales le otorgaban a la época faraónica. ${ }^{9}$ Además, subyacía a esto la idea de que el antiguo Egipto había alcanzado la civilización y la historia posterior sólo representaba un desvío o estancamiento en relación a ese pasado, y, por lo tanto, condenaba al Egipto no faraónico a una eternidad de ser visto como inferior a la modernidad occidental. ${ }^{10}$
8. Una notable excepción es Zainab Bahrani (2003), quien cuestiona el uso del constructo "Mesopotamia" a favor de "Babilonia" o, en un sentido más amplio, Asiria/Babilonia. En un trabajo posterior, Bahrani (2006) discute sobre la aplicación de cierta taxonomía elaborada para el estudio de las dinámicas étnicas en la antigüedad y sostiene que se ha empleado una terminología "racista" para su abordaje. Asimismo, los estudios realizados por Katia Pozzer (2018) sobre la imaginería visual neo-asiria van en dicha tónica y se focalizan en algunas reapropiaciones culturales que se hicieron en Iraq a fines del siglo XX en el contexto de la Guerra del Golfo.

9. Cf. Reid (1985).

10. Cf. Carruthers (2014). 
11. Miller (2005, p. 5). Con anterioridad, Daniel Miller (1987) había señalado la dificultad que implicaba la reflexión teórica sobre cómo los artefactos estaban relacionados con el proceso de constitución cultural y, por extensión, a los diferentes vínculos interpersonales. Posteriormente, el mismo autor editó una obra en la que compilaba un conjunto de artículos que reflexionaban sobre la "cultura material”, cf. Miller (1998).

12. Cf. Hicks (2010).

13. Rede (1996; 2001; 2018). También, sobre este tópico, cf. Cabrera (2019).

14. Moser (2006).

15. Cf. Reid, op cit.; Meske11 (2020).

16. Cf. Moser, op. cit.; Riggs (2010). Para el caso de Gran Bretaña, cf. Stevenson (2015).

17. El concepto de "biografía de los objetos" ha sido discutido inicialmente por Arjun Appadurai (3-63) y, con posteridad, fue retomado por Chris Gosden e Yvonne Marshall. Cf. Appadurai (1986); Gosden y Marshall (1999). Asimismo, cf. Hicks, op. cit. y consultar la discusión planteada en la nota 11. Existen otros artículos recientes sobre el te$\mathrm{ma}$, los cuales hacen foco en la capacidad agencial y determinante/dominante de los objetos. Cf. Robb (2015; 2020) y Eaton (2020).

\section{SEGUNDO PUNTO: LA COLONIZACIÓN DE LOS OBJETOS CULTURALES Y SU TRANSFORMACIÓN EN ARTEFACTOS MUSEOLÓGICOS}

Una noción clave para entender el funcionamiento de las metáforas coloniales y su vinculación a la construcción de determinados saberes -y narrativas asociadas- es la de "materialidad". En principio, el concepto materialidad, acuñado por la Antropología anglosajona durante los años noventa, supone una revisión de la dialéctica sujeto/objeto y, en alguna medida, otorgarle a las piezas museologizables -según la lente colonialista- una capacidad agencial. Siguiendo a Daniel Miller, la materialidad

implica que mucho de lo que somos existe no por medio de nuestra conciencia o cuerpo, sino como un ambiente exterior que nos habita y estimula. Esta capacidad algo inesperada de los objetos para desvanecerse y permanecer periféricos a nuestra visión y todavía ser determinantes de nuestra conducta e identidad tendría otro resultado importante. ${ }^{11}$

Existe una diversidad de artículos en los corpus bibliográficos antropológicos y arqueológicos que indagan sobre los conceptos "cultura material" y "materialidad". 12 A propósito, los Estudios de la Cultura Material, los cuales nacieron a partir de la anterior discusión conceptual, plantearon una reconciliación hermenéutico-epistemológica del estructuralismo con la Semiótica y la Teoría de la Práctica de Pierre Bourdieu y Anthony Giddens. En el ámbito de la Historia, no aconteció lo mismo. Una buena excepción a la regla son las discusiones planteadas en los trabajos del asiriólogo Marcelo Rede, quien analiza los conceptos de "objeto", "documento", "artefacto", entre otros, y focaliza en cómo los textos pueden ser abordados dentro de la cultura material. ${ }^{13}$

Desde el Renacimiento europeo, según lo ha analizado en profundidad Stephanie Moser, los artefactos provenientes de Egipto fueron fundamentales en los primeros pasos del coleccionismo, precursor de los museos de los siglos XVIII-XIX. ${ }^{14}$ El desarrollo del imperialismo, la rivalidad entre las potencias y los intereses colonialistas sobre Egipto profundizaron la Arqueología egipcia. ${ }^{15}$ La obtención de objetos en el campo, como parte del trabajo arqueológico, siguió una lógica inserta en el museo, pero no sólo el artefacto, sino también los documentos y quienes tienen la capacidad de interpretación deben ser considerados dentro de la formación de los museos y sus colecciones. ${ }^{16}$

En relación a este último punto, todo objeto posee su propia historia de vida o "biografía" 17 y, por lo tanto, al verse despojado de su contexto inicial -tanto de 
producción, circulación y/o almacenamiento- experimenta un proceso de extrañamiento y, luego, una reasignación de significado en los museos (Figura 1). Subsidiaria de esta definición es el concepto de "habitus material", acuñado por Lynn Meskell al vincular la perspectiva de Pierre Bourdieu con la de Daniel Miller -incluso con las ideas de Edward B. Tylor. ${ }^{18}$ Siguiendo a esta autora, "[l]a idea de un mundo de vida material que concebimos y construimos nosotros, pero que igualmente configura la experiencia humana en la praxis diaria, es provocativa." 19

La construcción del habitus material de los objetos culturales, devenidos en artefactos museológicos a partir del contexto del imperialismo del siglo XIX, refleja de qué manera el despojo de los países de Asia y África de sus respectivos legados históricos contribuyó en la cimentación de una identidad europea supranacional. La misma se erigió en un equivalente de civilización y supremacía étnica, y necesitó de la ruptura de las tramas identitarias de las sociedades nativas a partir de la descontextualización de sus objetos culturales. Más trágico todavía fue el despojo material de las sociedades nativas, el cual contribuyó en su proceso de deshistorización y que se dio a través del quiebre abrupto de su nexo con el pasado.

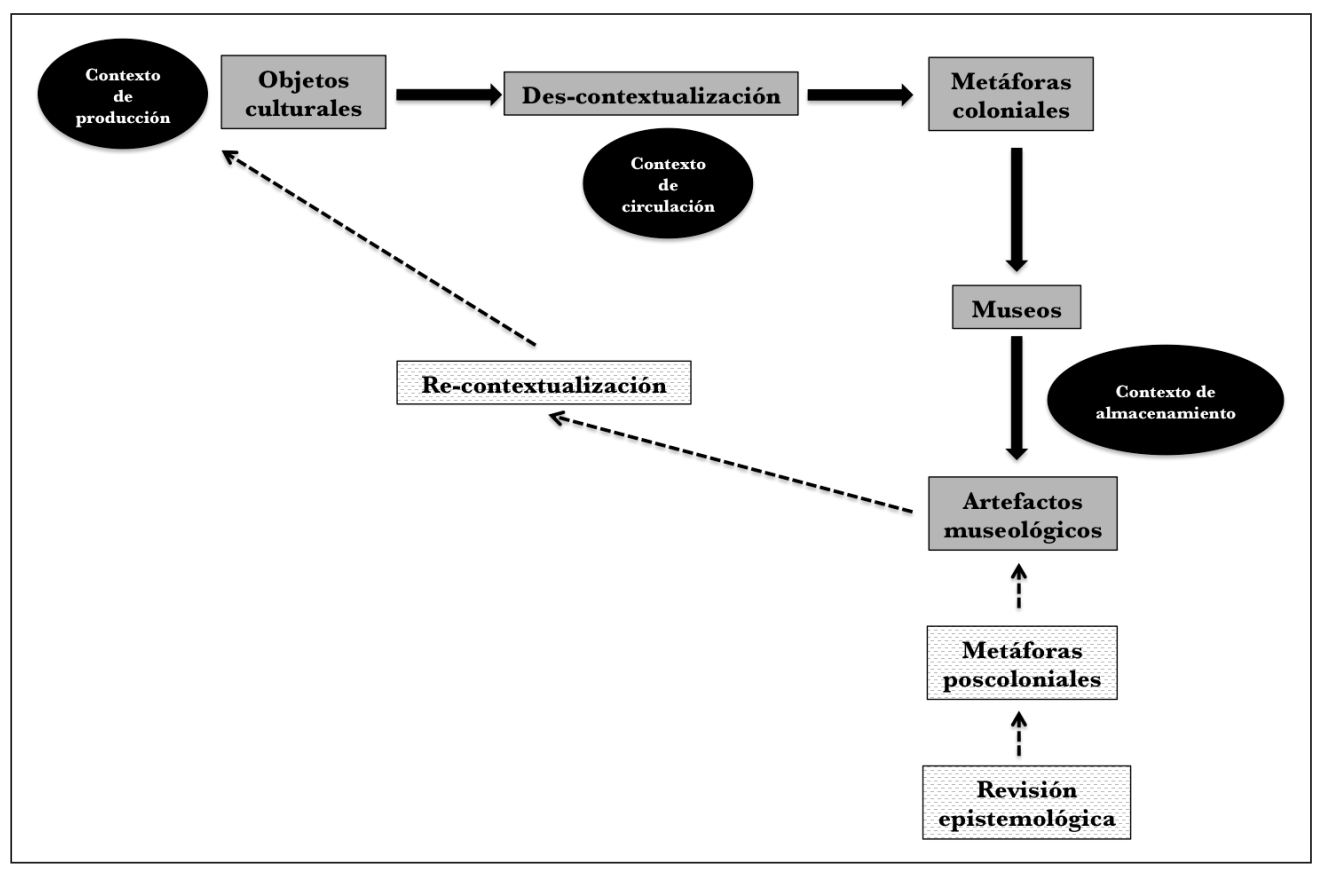

Figura 1 - De objetos culturales a artefactos museológicos.

La figura precedente contempla las distintas instancias que transforman a los objetos culturales en artefactos museológicos por medio de las metáforas coloniales producidas en los contextos científicos europeos. De esta manera, el museo se 
20. Hodder (2011).

21. Ibid. yergue no sólo como el receptáculo final (o contexto de almacenamiento), sino, además, en calidad de instancia (re-)productora de un tipo de agencia colonizadora y como el escenario necesario para la dramatización y actualización de la empresa imperial. Ante la pérdida de identidad por parte de los objetos culturales en el proceso de circulación y expolio de las naciones colonizadas, la revisión epistemológica actual -y que aquí proponemos- tiene la obligación de cooperar con el proceso de re-contextualización de los ahora artefactos museológicos. No obstante, ante el vacío que existe en muchos casos en vinculación con las piezas atesoradas en las vitrinas de los museos, presentamos, en términos discursivos, una resemantización que interpele a las/los especialistas y las/los invite a dialogar (no por un efecto metafísico) con los contextos de producción inicial de los objetos culturales y, además, con las sociedades que los elaboraron.

Por otro lado, en un universo de relaciones que superan la dialéctica sujeto/ objeto, también podemos pensar en la noción de entanglement de lan Hodder, por medio de la cual, encontramos el siguiente juego de vínculos entre humanos y "cosas": (a) los humanos dependen de cosas; (b) las cosas dependen de otras cosas; y (c) las cosas dependen de los humanos. ${ }^{20}$ De ahí deriva el concepto de entanglement, traducido por alguna bibliografía como "enredo", pero que sirve para deconstruir los relatos colonialistas que han transformado a los objetos culturales específicos en artefactos museológicos y los han despojado de su contexto inicial de significación. ${ }^{21}$

A pesar de ello, un museo en calidad de espacio generador de agencia colonialista, si bien participa de la destrucción del modelo rizomático del entanglement inicial y del proceso de des-contextualización mediatizado por las metáforas coloniales y la praxis imperialista, también podría involucrar, en la actualidad, la acción de recontextualización/resemantización vehiculizada por las metáforas poscoloniales nacidas a partir de los Estudios Subalternos. Para ello, necesitamos de la vigilancia epistemológica activa de quienes participan del proceso de investigación, no como meras/os reproductoras/es y descriptoras/es de agencia colonialista.

En un siguiente apartado, se analiza cómo esos mismos relatos coloniales fueron asumidos y reproducidos por la élite cultural europea, y, posteriormente, se retomaron por las clases altas de Latinoamérica, despojando a los países de Asia y África-e, incluso, a las comunidades indígenas de América- de su propio acervo cultural. Se estudiarán las metáforas de un Oriente bárbaro e incivilizado en tanto elemento constitutivo para la selección, exhibición y formación de las primeras salas de museos en relación a la Historia y Arqueología antiguo-oriental. Este recorrido nos permitirá discutir cómo el museo se presentaba en tanto espacio civilizador y, a la vez, generador de agencia colonialista. 


\section{TERCER PUNTO: EL DIVORCIO DE LA ASIRIOLOGÍA Y LA EGIPTOLOGÍA DE LAS HUMANIDADES}

Teniendo en cuenta los dos apartados precedentes, el presente trabajo pone en cuestionamiento cómo en Europa las ideas de dominación imperialistas y colonialistas fueron parte "de un modo" de construir y disponer de Oriente en la exhibición de objetos, en la constitución de los museos y el origen y desarrollo de Ciencias Humanas relacionadas con la Arqueología e Historia antigua de Oriente, las cuales reciben el nombre de Ancient Near East studies (de ahora en adelante ANE studies), "Estudios del Próximo Oriente antiguo", "Estudios Orientales" o, simplemente, "Orientalística". 22

En cuanto al desarrollo de las Humanidades a lo largo del siglo XIX y, en especial, en lo referente a los denominados ANE studies, podemos mencionar a cuatro países europeos que tomaron la delantera en la definición de la Egiptología y la Asiriología como campos académicos: Inglaterra, Francia, Alemania e Italia. Posteriormente, se sumaron los Estados Unidos.

Con anterioridad a las modas académicas del siglo XIX, se reconoce un interés previo por Oriente, sobre todo por los denominados viajeros europeos. A partir del romanticismo, se comenzó a construir una visión exótica de Oriente, un espacio de libertades, que podemos registrar en la pluma de Lord Byron, Johann Wolfgang von Goethe y/o Victor Hugo. ${ }^{23}$

Por otro lado, Oriente no implicó lo mismo para los visitantes provenientes de Inglaterra que para aquellos oriundos de Francia: mientras que, para los primeros, Oriente se erigió en sinónimo de India-posteriormente, del espacio entre esta y el Mediterráneo- y, por consiguiente, de posesión material y real de los territorios, para los franceses, era un espacio de nostalgia por un paraíso colonial perdido ante los británicos luego de las derrotas napoleónicas. ${ }^{24}$

Tanto la Egiptología como la Asiriología se desarrollaron al calor de las aproximaciones primarias a textos en jeroglífico y cuneiforme, y, en paralelo, a las competencias imperialistas que los desciframientos de ambos sistemas de escritura generaron para cada compartimento académico. Asimismo, las dos disciplinas se constituyeron en saberes particularmente filológicos y que se diferenciaban claramente de la Arqueología, la cual se abocó hacia el trabajo de campo y la búsqueda incesante de grandes tesoros, acaparados por los museos de Europa.

De esta manera, se produjo un primer gran divorcio disciplinar y una híperespecialización que se mantuvo hasta la actualidad, dando origen a una serie de consecuencias: en principio, la diferenciación de los ANE studies de la "Historia
22. Esto dio lugar a la conformación de diferentes grupos y/o sociedades abocadas al estudio de las poblaciones de Oriente antiguo desde mediados del siglo XIX en Europa y Estados Unidos. Por ejemplo, la primera cátedra universitaria asociada a la Asiriología en la Universidad de Londres se dio con el nombramiento de Theophilus Goldridge Pinches del British Museum como profesor. Otros organismos vinculados a los ANE studies en Europa y Estados Unidos son: Société Asiatique (París, 1822), Royal Asiatic Society of Great Britain and Ireland (Londres, 1823), American Oriental Society (Massachusetts, 1842), Deutsche Morgenländische Gesellschaft (Leipzig, 1845), Institut Français d'Archéologie Orientale (El Cairo, 1880), Egypt Exploration Society (Londres, 1882), Deutsche Orient-Gesellschaft (Berlín, 1898), American Schools of Oriental Research (Boston, 1900), Deutsches Archäologische Institut (El Cairo, 1907), Oriental Institute (Chicago, 1912), British Institute for the Study of Iraq (Londres, 1932), Councilfor British Research in the Levant (Jerusalén y Amán, 1998), The Melammu Project/The Assyrian and Babylonian Intellectual Heritage Project (Helsinki, 1998), entre otras.

23. Sobre este punto, se puede consultar Said (1978).

24. Ibid. Asimismo, la imagen que se construyó sobre Egipto a lo largo de la historia fue variada y ambigua, los parámetros que lo definieron (y hoy en día lo definen) no son neutrales ni están dados en términos objetivos, sino que responden a construcciones culturales. Cf. Ucko y Champion (2003). 
25. En algunas universidades, si bien las ofertas de estudios de grado y posgrado conservan, en un primer momento, asignaturas comunes a los ANE studies y la Historia antigua, en una instancia ulterior, se da una clara separación curricular. Por ejemplo, esto se observa en varias universidades alemanas que ofrecen Orientalistik (Estudios Orientales), Geschichtswissenschaft (Historia) y Jüdische Studien (Estudios Judíos).

26. De hecho, actualmente, en las diferentes universidades europeas y norteamericanas, las cuales cuentan en sus estudios de grado (B.A.) como de posgrado (M.A. y Ph.D.) con carreras orientadas directamente a los ANE studies, tanto la Egiptología como la Asiriología son disciplinas estrictamente filológicas, diferenciadas de la Arqueología.

27. La discusión sobre el proceso de colonización y su vinculación con la acumulación capitalista originaria puede encontrarse en una amplia bibliografía marxiana y marxista. No obstante, dado los objetivos y enfoque del presente artículo, consideramos que los debates al interior de los Estudios Subalternos ofrecen un marco de referencia más a tono con nuestra propuesta. Por un lado, al pensar la noción de "centro-periferia”, Aníbal Quijano sostiene que el capitalismo siempre fue "colonial/moderno y eurocentrado". Por consiguiente, con el desarrollo capitalista y la conquista y colonización de América, Asia y África sobrevino "un proceso de re-identificación histórica, pues desde Europa les fueron atribuidas nuevas identidades geoculturales" (Quijano, 2004, p. 201).

28. Gooch (1913).

29. Ibid., p. 496. antigua" 25 y, por otro, de la Arqueología. En segundo término, ocurrió la asociación estricta entre ANE studies y Filología, aunque con una praxis ajena a las transformaciones que se dieron en el ámbito de la Lingüística. ${ }^{26}$ Este primer divorcio académico y, también, disciplinar significó para los ANE studies transformarse en una rareza y, a la vez, una diferenciación de lo que se consideraba Historia antigua, asociada esta última a los desarrollos específicos de Grecia y Roma. De algún modo, Europa se quedó con la Historia y, por otro lado, Asia y África -en tanto "rarezas" - se transformaron en un Oriente exótico y que necesitaba ser colonizado por la academia. ${ }^{27}$

A propósito, y como una buena excepción, George Gooch, en History and Historians in the Nineteenth Century, ${ }^{28}$ se refiere a los estudios específicos de Egipto y la Mesopotamia asiática dentro del campo de la Historia mundial. El capítulo XXV de su libro, el cual se titula "El antiguo Oriente" ("The Ancient East"), alude a las "civilizaciones" "egipcia", "babilónica", "cretense" e "hitita" respectivamente, haciendo mención de los distintos descubrimientos en torno al registro material y el escrito. El capítulo concluye con un apartado referido a los árabes, los persas y los indios. De forma optimista, la sección dedicada al antiguo Oriente comienza del siguiente modo:

Uno de los acontecimientos más sensacionales del siglo XIX es la resurrección del antiguo Oriente. Sabemos ahora que Grecia y Roma, lejos de hallarse situadas cerca del comienzo de la historia conocida, fueron herederas de una larga serie de brillantes civilizaciones. Toda nuestra perspectiva ha cambiado. El mundo antiguo deja de ser el vestíbulo de la Europa cristiana, convirtiéndose en cuanto a duración en la parte más extensa de la historia humana. ${ }^{29}$

Dicho capítulo se ubica luego de uno titulado "Grecia y Bizancio" y antes de otro que se denomina "Los judíos y la Iglesia cristiana", y establece una serie de planteos y recorridos por la historia de Oriente a partir de los conocidos "grandes descubrimientos" del momento. En ese mismo libro, George Gooch también menciona a los considerados padres de la Historia en Europa y, obviamente, le dedica uno de los primeros capítulos al historiador alemán Leopold von Ranke.

Al respecto de estos recorridos historiográficos, Enrique Dussel sostiene que la historia asiática fue asumida como parte de la prehistoria de Europa, en tanto producto "ideológico" del eurocentrismo romántico alemán. ${ }^{30}$ De ese estadio, se avanzaría a los siguientes: "mundo griego", "mundo romano pagano y cristiano", "mundo cristiano medieval" y "mundo europeo moderno". ${ }^{31}$ En relación con este 
argumento y en una crítica a la noción geo-cultural wallersteniana, Walter Mignolo sostiene que la colonialidad es un rasgo propio de la modernidad y no sólo en términos económicos sino que obviamente involucra otras esferas sociales. ${ }^{32}$ En ese sentido, la "diferencia colonial" de la que habla Mignolo para repensar el concepto de geo-cultura no se restringe al proceso socio-histórico que termina encumbrando a las potencias del Atlántico Norte (Francia e Inglaterra) como lo piensa Immanuel Wallerstein, sino que contempla a la colonización española y portuguesa en tanto iniciadoras de esa nueva forma de dominación propia de la modernidad. ${ }^{33}$

Por tal motivo, el momento en que los ANE studies se divorciaron académicamente de las otras disciplinas humanísticas y, en particular, de la Historia, fue la instancia en que se transformaron en un conjunto disciplinar en que la teorización y las discusiones metodológicas eran casi inexistentes, aunque podemos observar grandes excepciones a la regla.

A propósito, y sobre todo en las dos primeras décadas del siglo XXI, hubo una necesidad imperiosa, tanto al interior de la Egiptología como de la Asiriología, por repensarse en cuanto disciplinas académicas, primas cercanas de la Historia, la Arqueología y la Filología. A propósito, Juan Carlos Moreno García se refiere a la Egiptología como una disciplina "maldita", puesto que, a diferencia de la Asiriología, continúa atrayendo el interés egiptomaníaco en detrimento del científico. ${ }^{34}$

En el Renacimiento, se produce tanto la génesis de la Egiptología como de la egiptomanía, en tanto que la curiosidad de los humanistas italianos lleva a un (re-) descubrimiento de Egipto, especialmente, con el estudio renovado, la traducción de textos y el intento de la lectura de los jeroglíficos. Este fenómeno impulsó una renovada mirada e interés por la ciencia y la magia egipcias, la colección de objetos, el hermetismo y el uso de motivos egipcios en el arte y la arquitectura. Ronald Fritze afirma que fue una combinación de estos fenómenos los que asentaron la base de la egiptomanía, muchos de los cuales todavía siguen siendo parte de nuestra cultura contemporánea. ${ }^{35}$ La admiración y fascinación por Egipto es claramente anterior a la ocupación y apropiación imperialista de los siglos XIX y comienzos del XX. ${ }^{36}$

Debido a este impulso egiptomaníaco, la Egiptología se ha distanciado en buena medida de ciertas temáticas concernientes a la Historia económica y social, cuestión que la Asiriología ha logrado sortear y trascender así la etiqueta filológica. ${ }^{37}$ Por otra parte, esta última tiene diversos exponentes que han hecho foco en discusiones de Historia social a partir de objetos poco atractivos para la lente no especializada -como las tablillas de arcilla con textos cuneiformes-, ${ }^{38}$ mientras que la Egiptología aún continúa centrando su atención en la exhumación de objetos considerados bellos y atractivos. De este modo, una Arqueología
30. Dussel, op. cit.

31. Ibid., p. 42 .

32. Mignolo (2004).

33. Ibid.

34. Moreno García (2014)

35. Fritze (2016).

36. Cf. Moser, op. cit. y Colla, op. cit. específicamente para el caso de las colecciones del British Museum.

37. Moreno García, op. cit. No obstante, la Asiriología se asume de forma casi unánime como una asignatura filológica. Asimismo, se la vincula con un abordaje de cuestiones esotéricas, tanto por el público general como por el resto de los parientes disciplinares más próximos. Cf. discusión en Westenholz (2006).

38. Afortunadamente, a pesar del fuerte peso filológico en Asiriología, se han dado discusiones teórico-metodológicas en las que se ha planteado la validez de modelos analíticos provenientes de otras disciplinas cercanas como la Antropología, la Sociología y la Historia social, así como también sobre el uso de enfoques y/o perspectivas, como la reciente publicación de Mario Liverani (2013) sobre la ciudad en la antigüedad. Del mismo tenor, encontramos otros trabajos que indagan sobre la necesidad de construir una Historia política de Mesopotamia -al respecto, cf. Richardson (2014)-, que hacen foco en una Historia social en el marco de la Asiriología -cf. Rede (2007a, 2007b) - o que incluso plantean escribir una Historia "desde abajo" -cf. Van de Mieroop (1999). 
39. Moreno García, op. cit., p. 58.

40. Pereyra y Zingarelli (2003). Asimismo, de reciente aparición, se encuentra un trabajo de Andrea Zingarelli sobre la aplicación del modo de producción asiático para el análisis de las relaciones socioeconómicas en el antiguo Egipto. Zingarelli (2015).

41. Richards (2009).

42. Nyord (2019).

43. Cf. Smith (1995; 2003).

44. Cardoso (1982; 1987). revista de un "aura romántica" aún se presenta como hegemónica en el abordaje de la historia del país africano y,

[...] a pesar de la preocupación por la rápida destrucción de los asentamientos antiguos en Egipto, particularmente en el delta del Nilo, muchos egiptólogos todavía prefieren centrar su atención en la excavación de tumbas (potencialmente) ricas en el Alto Egipto o el área de menfita. ${ }^{39}$

Aunque se pueden reconocer diversos trabajos en Egiptología que hacen abordajes sobre la Historia social a partir del estudio del registro funerario. Por ejemplo, Violeta Pereyra y Andrea Zingarelli se focalizan en el estudio de la información de tumbas del Reino Nuevo para discutir las formas de tributación del período, sustentando la investigación en una fuerte discusión teórica y filológica. ${ }^{40}$ Otros estudios más recientes sobre el antiguo Egipto no se orientan únicamente a presentaciones descriptivas de los registros arqueológicos provenientes de tumbas. A propósito, la propuesta de Janet Richards se dirige al entendimiento de la organización social en base a una mirada renovada en relación a las clases sociales intermedias a partir del análisis de la evidencia de los enterramientos en el Reino Medio, especialmente, en Abidos. ${ }^{41}$ Las prácticas y creencias mortuorias están siendo revisadas en el marco del "giro ontológico" por Rune Nyord, desarticulando ideas naturalizadas por las/los investigadoras/es acerca del Más Allá. ${ }^{42}$

Además, en las últimas décadas, también se está replanteando la centralidad que han tenido ciertos espacios en la configuración y mantenimiento del Estado en el antiguo Egipto, considerando otras variables como las dinámicas poblaciones y otras localizaciones como Nubia. ${ }^{43}$

Por otro parte, la trayectoria académica de Ciro Flamarion S. Cardoso es un ejemplo ilustrativo de la importancia de la formación en Historia social para los Estudios de Oriente. Aunque su área de desempeño por excelencia fuera el antiguo Egipto, se encargó de efectuar trabajos críticos en un ámbito historiográfico mucho más amplio. ${ }^{44}$ Su obra ha sido prolífica en el entorno científico latinoamericano no sólo por sus publicaciones sino también gracias a la vasta formación de recursos humanos, sobre todo, en las universidades brasileñas.

Afortunadamente, este tipo de reflexiones y revisiones teórico-metodológicas se están dando en diferentes ámbitos académicos en relación a los ANE studies, tal como lo señala la celebración de encuentros especializados O, también, la propuesta de workshops focalizados en Historiografía y que permiten repensar la construcción interna de cada disciplina en congresos internacionales de Egiptología o Asiriología. 
A propósito, en el mundo de habla hispana, si bien dichas cuestiones también han empezado a debatirse, el castellano y/o el portugués son lenguas marginales en la producción académica de los ANE studies. Cuenta de ello es el libro editado por Rocío Da Riva y Jordi Vidal, ${ }^{45}$ producto de un workshop celebrado en Barcelona en 2013, en el que se recogen artículos de varios especialistas en lengua castellana, quienes reflexionan sobre la construcción de los Estudios Orientales en varios países de Europa. ${ }^{46}$ Algunos de los trabajos apuntan a debates historiográficos, otros a diferentes reflexiones teóricas y metodológicas, y, mayoritariamente, los autores realizan indagaciones sobre determinadas figuras de la academia que se consideran pioneras en los Estudios Orientales. A propósito, Jordi Vidal señala la incorporación de España a la producción de los ANE studies, aunque también resalta su lugar "periférico". 47 Por otra parte, considera que la reflexión disciplinar al interior de los ANE studies se ha comenzado a realizar desde una impronta biográfica -en la que se destaca, por ejemplo, el caso inglés-, priorizando aquellas figuras que se presentan como pioneras y, a la vez, en diálogo con la historia nacional de cada país. ${ }^{48}$

En cuanto a la Asiriología, podemos reconocer una serie de trabajos y discusiones, sobre todo en las últimas décadas, sobre la disciplina y las maneras de abordar -tanto desde lo teórico como lo metodológico- el conjunto de problemáticas propias de la sociedad mesopotámica en la antigüedad. Una mención inicial o, mejor dicho, una primera observación a la manera en que los asiriólogos construían los relatos sobre las sociedades antiguas de Mesopotamia, la encontramos en Samuel Noah Kramer:

Los sumerios, es seguro decir, no produjeron historiografía en el sentido generalmente aceptado de la palabra. Ciertamente, ningún hombre de letras sumerio escribió la historia como la concibe el historiador moderno, en términos de procesos de desarrollo y principios subyacentes. ${ }^{49}$

Si bien la referencia previa alude al contexto de las escuelas de escribas y, por consiguiente, al núcleo productor de conocimiento y preservador de la memoria cultural, se plantea una manera diferente en la cimentación de los relatos por aquellos "hombres de letras sumerios". Una observación semejante realiza A. Leo Oppenheim años más tarde:

Hay una notable ausencia de literatura histórica, en el sentido de que faltan textos que den fe de la conciencia de los escribas de la existencia de un continuum histórico en la civilización mesopotámica del que ellos mismos y su tradición eran sólo una parte. ${ }^{50}$
45. Da Riva y Vidal (2015).

46. En el ámbito español, se celebraron congresos específicos previos al mencionado, los cuales dieron como resultado la publicación de varios números monográficos. Cf. Córdoba Zoilo, Jiménez Zamudio y Sevilla Cueva (2001) o Córdoba Zoilo y Pérez Díe (2006 $\left.{ }^{\mathrm{a}}, 2006 \mathrm{~b}\right)$. En dichas producciones, el foco estuvo puesto en el desarrollo español de una Arqueología de campo en Egipto y el Próximo Oriente, así como también en la reflexión sobre los viajeros y pioneros de la disciplina.

47. Vidal (2015). En cuanto a la noción de "periférico", consideramos más oportuno hablar de "subalterno" dado que implica un posicionamiento político $\mathrm{y}$, a la vez, marca el grado de colonialidad en cómo se estructura también el ámbito académico. En efecto, hay saberes "legítimos" (o eurocentrados en los términos de Aníbal Quijano) que se redactan en inglés, alemán y francés. Curiosamente, en las publicaciones brasileñas, debemos destacar el predominio de la lengua portuguesa en las producciones y la respectiva defensa de la formación de recursos humanos hacia el interior del sistema. El caso argentino es diferente, dado que, en las publicaciones especializadas en Estudios de Oriente, hay una notable hegemonía de las lenguas eurocentradas en consonancia con determinados lineamientos editoriales que desestiman la proyección académica local.

48. Ibid. En cuanto al uso del género biográfico, el cual constituye un recurso apropiado para efectuar una historia inicial de la disciplina, pueden citarse diversos estudios. Asimismo, a diferencia de lo que ocurre con 
otros devenires académicos, como ocurre en la Historia misma, los ANE studies todavía permanecen en una etapa muy embrionaria de discusión y reflexión interna, aunque podemos encontrar excepciones.

49. Kramer (1956, p. 32).

50. Oppenheim (1960, p. 413).

51. Finkelstein (1963).

52. Ibid., p. 462.

53. Algunos estudios indagan sobre la definición del Orientalismo y/o la Asiriología como disciplinas académicas. Cf. Bottéro (1982), Fales (2006), Westenholz, op. cit., Démare-Lafont (2008) y Vita (2012). Otros trabajos apuntan al abordaje de determinadas problemáticas, referidas a cuestiones de índole étnica o lingüística. Cf. Cooper (1991) y Abrahami (2007). Asimismo, se encuentran artículos que hacen foco en el análisis de la Asiriología en base a determinadas publicaciones y/o trabajos de campo emprendidos por especialistas, tanto a quienes pueden ser considerados como pioneros, e.g. Manuel Molina sobre el arqueólogo británico Leonard Woolley o Dominique Charpin sobre la figura del semitista francés Ernest Renan, así como aquellos que han contribuido a discusiones más actuales, e.g. Ariel M. Bagg sobre un trabajo del asiriólogo alemán Walter Mayer. Bagg (1998), Molina (2010) y Charpin (2013). De forma reciente, también han aparecido indagaciones sobre otras regiones dentro de los ANE studies que incluyen, por ejemplo, abordajes más localizados como la región del actual Irán, la cual se presenta en una frontera disciplinar entre la Asiriología y los Estudios Iranios. Cf. Basello (2004).
De todos modos, una primera mención a una "Historiografía" en vinculación a los estudios referidos a Mesopotamia la podemos encontrar en un artículo de Jacob J. Finkelstein, en el que el autor dialoga con los trabajos de los anteriores y, curiosamente, plantea una relación con la propuesta del historiador británico Edward H. Carr. ${ }^{51}$ En palabras de Jacob J. Finkelstein:

Pero el presente artículo no pretende ser un discurso más sobre los males del occidentocentrismo. Sin embargo, nos veremos obligados a reflexionar un poco sobre nuestras definiciones y conceptos historiográficos más básicos, si queremos decir algo sobre la historiografía mesopotámica que sea significativo para el historiador occidental y que, al mismo tiempo, no distorsione la imagen del universo conceptual de los mesopotámicos (suponiendo que podamos entrar en él). 52

Más allá de esta primera crítica a las modas eurocéntricas sobre cómo se escribía -y escribe-la Historia de los pueblos de Asia y África, el trabajo de Jacob J. Finkelstein, si bien se refería a una Historiografía, se presenta más bien como una necesidad de entender a los mesopotámicos a partir de sus propias producciones textuales más que a las interpretaciones desde un enfoque científico.

En las décadas siguientes, podemos encontrar artículos de especialistas que comenzaron a realizarse preguntas sobre la Asiriología y la Egiptología en tanto disciplinas y sobre los ANE studies en líneas generales. ${ }^{53}$ A propósito, en la Rencontre Assyriologique Internationale -el evento anual más importante en Asiriología- del año 1998, el tópico discutido fue la "Historiografía". Los resultados del encuentro fueron editados y publicados en el 2001 por Tzvi Abusch et al. ${ }^{54}$

Por otra parte, para la Egiptología, son conocidas las reediciones de Morris Bierbrier, Who Was Who in Egyptology. ${ }^{55}$ En una primera instancia, la pregunta por la historia de la disciplina giró en torno a quiénes eran considerados personajes relevantes dentro de ella, especialmente europeos. De hecho, en la primera edición de Who Was Who, se excluyó el nombre del egiptólogo egipcio Ahmed Kamal.

En cuanto a personajes reconocidos, algunas obras de referencia son las siguientes: la de Warren Dawson en relación a la vida de Charles Wycliffe Goodwin; 56 la de Thomas James vinculada a Howard Carter y el hallazgo de la tumba de Tutankhamon; ${ }^{57}$ la de Jeffrey Abt para la vida de James Breasted y la creación del Oriental Institute. ${ }^{58}$ Existen, además, algunos estudios de caso circunscriptos principalmente a Gran Bretaña, Francia y los Estados Unidos. Por ejemplo, Suzanne Marchand, en relación al caso alemán, propone una indagación sobre los intelectuales que construyeron los estudios orientales entre 1830 y 1930.59 
Para el caso de Gran Bretaña, un trabajo clásico es el de John David Wortham, historia cronológica de la Egiptología británica desde mediados del siglo XVI hasta 1906, recuperando relatos de viajeros y primeros egiptólogos, 60 mientras que David Gange analiza cómo el antiguo Egipto se introdujo dentro de cultura británica en tensión constante con los estudios bíblicos. ${ }^{61}$ En tanto que el trabajo de John Wilson es uno de los primeros en proponer una historia de la Egiptología norteamericana. ${ }^{62}$

Más allá de estas referencias sobre personajes particulares o centrados en un país, la Egiptología está construyendo su propia historia y ha comenzado a repensar las prácticas y temas de estudios en clave historiográfica: cuáles son sus orígenes, qué límites presenta con otras ciencias, cuáles son sus aportes específicos, cómo fue construyendo un cientificismo delimitado con ciertas prácticas que la delinean como tal y qué reflexiones sobre su futuro en tanto disciplina se efectúa internamente. En este sentido, una obra reciente sobre el tópico es la editada por William Carruthers, Histories of Egyptology. ${ }^{63}$ El libro es un aporte fundamental para la historia de la Egiptología y, así, la contribución de egiptólogos egipcios con la recuperación de tradiciones y respuestas poscoloniales a la disciplina constituyen un aporte indispensable para poner en tensión los relatos tradicionales occidentales. En este sentido, Eliott Colla propone un estudio desde la Historia cultural y material para desentrañar el origen de la Egiptología entre Egipto y Europa. ${ }^{64}$ Su trabajo retoma fuentes árabes de primera mano, una crítica que se le había realizado a la obra de Timothy Mitchello5 en su estudio del poder y los métodos disciplinarios colonizadores sobre Egipto en el contexto del siglo XIX y la constitución de la Egiptología. ${ }^{66}$

\section{CUARTO PUNTO: EXOTIZAR ORIENTE Y CONSTRUIR EUROPA A PARTIR DE LOS OBJETOS, LOS MUSEOS Y LAS HUMANIDADES}

En la Europa del Renacimiento, el lugar ocupado por los objetos culturales de Oriente en las colecciones precursoras a las museos fue el de transmitir lo "exótico" y lo "raro" de las sociedades que los habías producido y eran clasificados por su material o función, en desmedro de la cronología y ubicación geográfica. ${ }^{67}$ Con el Renacimiento, los humanistas reviven el interés por el antiguo Egipto, pero no tuvieron acceso a los resultados que la Arqueología daría a finales del siglo XIX y la posibilidad de leer los jeroglíficos. Por lo tanto, el interés se transformó en fascinación y la falta de conocimiento dará como resultado la fantasía y la especulación. ${ }^{68}$ Esta forma de exposición daba cuenta del desconocimiento histórico
54. Abusch et al. (2001).

55. Bierbrier (2012).

56. Dawson (1934)

57. James (2001).

58. Abt (2011).

59. Marchand (2009)

60. Wortham (1971).

61. Gange (2013).

62. Wilson (1964).

63. Carruthers, op. cit.

64. Colla, op. cit.

65. Mitchell (1991).

66. Estas son sólo algunas de las obras de referencia en relación al desarrollo de la Egiptología y, si bien algunos ya son trabajos clásicos, apuntan a la discusión de la historia de la disciplina. Sin agotar toda la bibliografía, cf. Assmann (2005, 2014, 2017); Bierbrier, op. cit.; Carruthers (2011); Da Riva y Vidal, op. cit.; Dawson, op. cit.; Fritze, op. cit.; Gange, op. cit.; MacDonald y Rice (2009); Moreno García (2014, 2015); Parramore (2008); Reid (2002, 2016); Starkey y Starkey (1998); Tatomir (2015); Thompson (2015, 2016, 2018); Ucko y Champion, op. cit.; Wilson, op. cit.; Wortham, op. cit.

67. Cf. Stevenson, op. cit. 68. Cf. Fritze, op. cit. 
69. Cf. Assmann (2005); Fritze, op. cit.

70. Cf. Hobsbawm (2007).

71. Said, op. cit.

72. Cf. Ray (2008).

73. Cf. Fritze, op. cit.

74. Al respecto, el primer viajero por la región fue Pietro Della Valle (1614), al que le siguió John Chardin, de origen francés, a mediados del siglo XVII y visitó las ruinas aqueménidas en Persia. Luego, recorrió la zona el alemán Engelbert Kämpfer en el siglo XVIII, quien otorgó el nombre "cuneiforme" (Keilschrift) al sistema de escritura de Mesopotamia. de las antiguas poblaciones de Oriente, pero también reforzaba el sentido que sobre ellas se había construido a lo largo de los siglos XVII y XVIII: su exotismo y como parte de un saber especializado de religio dúplex en las sociedades secretas, el esoterismo y el ocultismo fueron claves en el acercamiento al antiguo Egipto. ${ }^{69}$

El exotismo ante los objetos culturales de Oriente -considerados "reliquias" - "antigüedades"- durante el siglo XIX se integró a las rivalidades colonialistas, especialmente entre Francia e Inglaterra, $y$, ante la conquista imperialista, los pueblos no europeos y sus sociedades eran considerados inferiores, atrasados, débiles, incultos y, por ello, debían ser convertidos a la "única civilización real", la occidental. ${ }^{70}$ En este contexto, la invasión napoleónica de Egipto en 1798 fue, como afirma Edward Said, un modelo perfecto de lo que es una verdadera apropiación científica por parte de otra cultura; ${ }^{71}$ en esta ocasión, la occidental sobre la oriental. En el caso de Egipto, este avance científico -que tuvo su edición escrita en la Description de l'Égypte- otorgó al Orientalismo su escenario, teatro y laboratorio para la experimentación y formación de un conocimiento colectivo sobre Oriente. Así, la invasión napoleónica, junto con el desciframiento de los jeroglíficos por parte de Jean-François Champollion tras el hallazgo de la Piedra Rosetta, ${ }^{72}$ se consideran el inicio de la profesionalización de la Egiptología como ciencia. Es decir, le puso un límite a las especulaciones y fantasías que se habían dado en torno a la interpretación de la historia del Egipto faraónico. Pero no finalizó con ella, la intensificación de la egiptomanía, entendida como la difusión, apropiación y consumo no científico de la historia faraónica, se profundizó durante esta etapa y, en los inicios de la Egiptología, se confundieron.

En este sentido, una de las miradas creadas desde la egiptomanía hacia Egipło giraron en torno a la fascinación. Por ejemplo, parecía exótico y enigmático cómo un cadáver podía permanecer durante siglos conservado en perfectas condiciones. La momiamanía representó el interés académico hacia las momias a lo largo del siglo XIX, tanto para estudiar las prácticas funerarias del Egipto faraónico, como en el marco de los estudios naturalistas que pretendían determinar/establecer a qué "raza" pertenecían los antiguos egipcios. Este fue el caso de Johann Friedrich Blumenbach, quien recibió tres momias del British Museum, haciendo del desenvolvimiento de las vendas de una momia un espectáculo cultural de gran popularidad. ${ }^{73}$

Un destino similar también corrieron las tierras entre el Éufrates y el Tigris, la región que los griegos llamaron Mesopotamia, pero a la que los viajeros y exploradores se habían dirigido, por un lado, en busca de respuestas vinculadas al mundo bíblico y, por otro, dada la circulación de un sistema de escritura "extraño" que ya se conocía desde el siglo XVII. ${ }^{74}$ Sin embargo, a diferencia del 
caso egipcio, el cual presentaba objetos culturales que despertaron la fascinación occidental, en Mesopotamia, las tablillas cuneiformes de arcilla no fueron piezas codiciadas en el mismo grado que los ajuares de las tumbas faraónicas. A pesar de ello, luego del desciframiento por Sir Henry Creswicke Rawlinson en 1835 de la llamada Inscripción de Behistún, que era trilingüe como la Piedra Rosetta, creció el interés por la historia de Mesopotamia. A ello, se sumaron los trabajos de campo emprendidos por diferentes países europeos, como los que realizaron el inglés Sir Austen Henry Layard y el francés Paul-Émile Botta en las antiguas capitales asirias, las cuales sacaron a la luz una gran diversidad de documentos en tablillas cuneiformes, como lo fue la biblioteca de Nínive. A esta fascinación orientalista, se incorporaron algunos experimentos europeos, como el desciframiento simultáneo en 1857 de un cilindro ortogonal correspondiente al rey asirio Tiglat-Pileser I por Sir Henry Creswicke Rawlinson, Edward Hincks, Julius Oppert y William Henry Fox Talbot. Como conclusión, los cuatro especialistas tuvieron resultados semejantes y se daba inició así a la Asiriología, una disciplina con un marcado enfoque filológico.

En efecto, el interés político y cultural que producía Oriente tuvo como consecuencia la búsqueda del control directo sobre África y Asia, y sus bienes culturales, respaldada por las ideas colonialistas. La ciencia se abrió paso por medio de la conquista y la posesión de territorios. ${ }^{75}$ De este modo, se produjo un aumento en el consumo de antigüedades orientales y la intensificación de excavaciones ilegales y la comercialización de piezas en el mercado negro. Esta práctica implicaba el saqueo sin ningún tipo de rigurosidad científica de sitios arqueológicos en busca de piezas egipcias y mesopotámicas, algunas de ellas, exhibidas en los museos, parques y salas privadas de Europa y los Estados Unidos. ${ }^{76}$

Pero, también, la Arqueología en Oriente a mediados del siglo XIX se definía como un trabajo de campo dentro del marco ideológico colonialista. Esta era una lógica que, de manera simultánea, estaba incrustada en la práctica del museo. ${ }^{77}$ Los estados imperialistas se beneficiaron de los conflictos colonialistas, involucrándose directamente en la adquisición de antigüedades a gran escala. La gran dimensión de las piezas, como lo fue para el caso del British Museum, sólo puede explicarse por el poder y el alcance de un estado imperial y militarista que intervenía y redireccionaba esfuerzos materiales y humanos hacia la constitución de las colecciones. ${ }^{78}$ Los museos, en particular los de Inglaterra y Francia, comenzaron rápidamente a adquirir piezas, las que fueron exhibidas de formas novedosas. ${ }^{79}$

La exhibición de Egipto y sus objetos culturales fue realizada en el marco del discurso del progreso de la civilización y, dentro de los sitios arqueológicos y los
75. Cf. Meskell (2020)

76. Cf. Fritze, op. cit.; Mitchell, op. cit.

77. Cf. Reid (2016); Stevenson, op. cit.

78. Cf. Hoock (2007)

79. Cf. Stevenson, op. cit.; Stevenson (2019). 
80. Cf. Colla, op. cit.

81. Colla, op. cit. La admiración y fascinación por esos objetos se transmite principalmente en los relatos de los visitantes a los museos y exhibiciones, y, en especial, en los relatos de viajeros a Egipto.

82. Cf. Colla, op. cit.

83. Cf. Petrie (1904).

84. Cf. Podgorny (2011).

85. Cf. Colla, op. cit.

86. Cf. Meskell (2020).

87. Bernal (1987). museos, se desenvolvieron los conflictos y las contradicciones de la modernidad, tanto para europeos como para egipcios. ${ }^{80}$ Siguiendo a Elliot Colla, los objetos egipcios en los museos potencializaban el espectáculo sobre el Egipto faraónico, no sólo de control y dominación, sino también de asombro y maravilla por el desarrollo artístico y cultural alcanzado por la civilización egipcia antigua. ${ }^{81}$ Al mismo tiempo que exhibirlos, era una de las formas de demostración del poder y el alcance del imperio británico, por ejemplo, a través de la Egyptian Sculpture Room.

Sin desconocer que, en las primeras décadas del siglo XIX, la interpretación de las antigüedades egipcias estuvo íntimamente relacionada con los debates sobre la historia bíblica, en este momento, se gesta la idea de "artefacto" para el antiguo Egipto en algún sitio entre el país africano y Londres. ${ }^{82}$ El trabajo de campo en el país africano era llevado adelante por los museos y universidades, las que también tenían sus propios establecimientos, como el caso de la Universidad de Oxford con el Ashmolean Museum. Por ejemplo, la Egypt Exploration Society reunía fondos para el trabajo en Egipto. En el campo, la Arqueología comenzaba a definir su método científico, lo que implicaba la adquisición y resguardo de los objetos por parte de los museos que dirigían las excavaciones, además de ficharlos y catalogarlos para que no se perdiera la información contextual de su hallazgo. ${ }^{83}$ El método que proponía William Flinders Petrie centraba el trabajo en la labor del arqueólogo para la construcción de datos y catálogos que contextualizaran los objetos hallados en la excavación. En una conferencia pronunciada ante los miembros de la Royal Society of Arts en 1900, el arqueólogo inglés relativizaba la importancia de las colecciones, dado que el problema que le preocupaba era la transmisión de los datos del campo a las vitrinas y depósitos de los museos, aduciendo que el trabajo del arqueólogo en el fichaje era más importante que las mismas colecciones. ${ }^{84}$ En su origen, el trabajo real de la Egiptología no estuvo del todo alejado del campo egipcio, aun cuando existía una línea clara entre el campo y la construcción de artefactos para los museos. ${ }^{85}$

La herencia de Europa occidental no podía competir con el pasado egipcio, es decir, con la complejidad del tiempo faraónico y su monumentalidad. Por lo tanto, con el colonialismo europeo -lo que se hace extensivo, a los Estados Unidos-, se tomó la iniciativa de apropiarse y cooptar la herencia egipcia en una construcción occidental de los orígenes de la civilización. ${ }^{86}$ El lugar de Egipto en el desarrollo de las sociedades civilizadas se estaba poniendo en discusión.

Martin Bernal analiza cómo el "modelo antiguo", el cual sostenía el pasado egipcio como génesis de la civilización, fue suplantado por el "modelo ario". ${ }^{87}$ Este último, que se sostuvo principalmente en Europa a lo largo del siglo XIX, daba cuenta de la Grecia clásica como la madre de la civilización, con la 
transmisión de un legado de la "raza aria" y el progreso como característica inherente a ella. Esto se debía a que,

[p]ara los románticos y racistas de los siglos XVIII y XIX, era sencillamente intolerable que Grecia, la cual se veía no sólo como el epítome de Europa sino también como su cuna, fuera el resultado de la mezcla de europeos nativos y africanos y semitas colonizadores. Por lo tanto, el modelo antiguo tuvo que ser desechado y reemplazado por algo más aceptable. ${ }^{88}$

En este momento, se creó una tradición narrativa sobre el origen y el posterior dominio de la civilización occidental sobre Egipto; 89 aquello que Juan Carlos Moreno García denomina como el "mito tenaz de la Egiptología". 90 En él, el pasado faraónico era considerado como progenitor de la civilización occidental, pasado que contrastaba con el declive y estancamiento que Egipto sufrió mientras el camino de la civilización avanzaba hacia Grecia. Esto significaba, especialmente, que la historia egipcia islámica no se consideraba dentro de los parámetros de la civilización. ${ }^{91}$ La posición subalterna que el Egipto moderno ocupaba, según Ellioł Colla, se explicaría por las ideas colonialistas sobre Oriente que se entrecruzaban en los comienzos de la Egiptología y la Arqueología como ciencias. ${ }^{92}$

En suma, los artefactos que fueron parte de las vitrinas y exposiciones de Europa occidental y los Estados Unidos pueden contar su propia historia. Esta historia no es únicamente la del Oriente antiguo, la que un académico desinteresado y ajeno a los vínculos constitutivos de sus objetos de estudio interpreta como fuente o evidencia del pasado. Principalmente, el artefacto cuenta una historia que se despliega y se enreda en una red de agentes-agencia, dando cuenta que las antigüedades orientales no fueron objetos pasivos en la historia. ${ }^{93}$ El colonialismo exigió y ejerció sobre ellos el poder de extraerlos, analizarlos, interpretarlos y exhibirlos (Figura 2). Por lo tanto, se plantea necesario (re-)situar las artefactos museológicos o antigüedades dentro de las metáforas coloniales que condicionaron, pero al mismo tiempo, crearon una interpretación ideológica y política que refiere a la historia de la modernidad que les dio lugar.
88. Bernal (1987, p. 2). A propósito, Martín Bernal fue objeto de diversas críticas a raíz de su libro Atenea negra, las cuales provinieron en particular del grupo de académicos de los ANE studies. Por ello, se editó un libro especial en el que el autor respondía a las críticas realizadas, Black Athena Writes Back, y, posteriormente, sacó el tomo III de Atenea negra correspondiente a los aspectos lingüísticos compartidos por las sociedades del Mediterráneo. Bernal (2001; 2006). Para otras críticas a su obra, cf. Marchand y Grafton, op. cit.

89. Carruthers (2011).

90. Moreno García (2015).

91. Oriente produjo siempre una gran fascinación y las ideas en torno a una tierra lejana y bárbara repercutieron y alimentaron el imaginario de la literatura argentina. Cf. Gasquet (2010), quien propone un recorrido por los principales representantes de la intelectualidad nacional. En relación a la literatura de viaje, cf. Salem (2018). En ese artículo, la autora aborda las problemáticas específicas en torno a Egipto y los primeros pasos de la Egiptología en Argentina.

92. Colla, op. cit.

93. Ibid. 
94. En relación con este punto, ver la discusión planteada en Cabrera, op. cit.

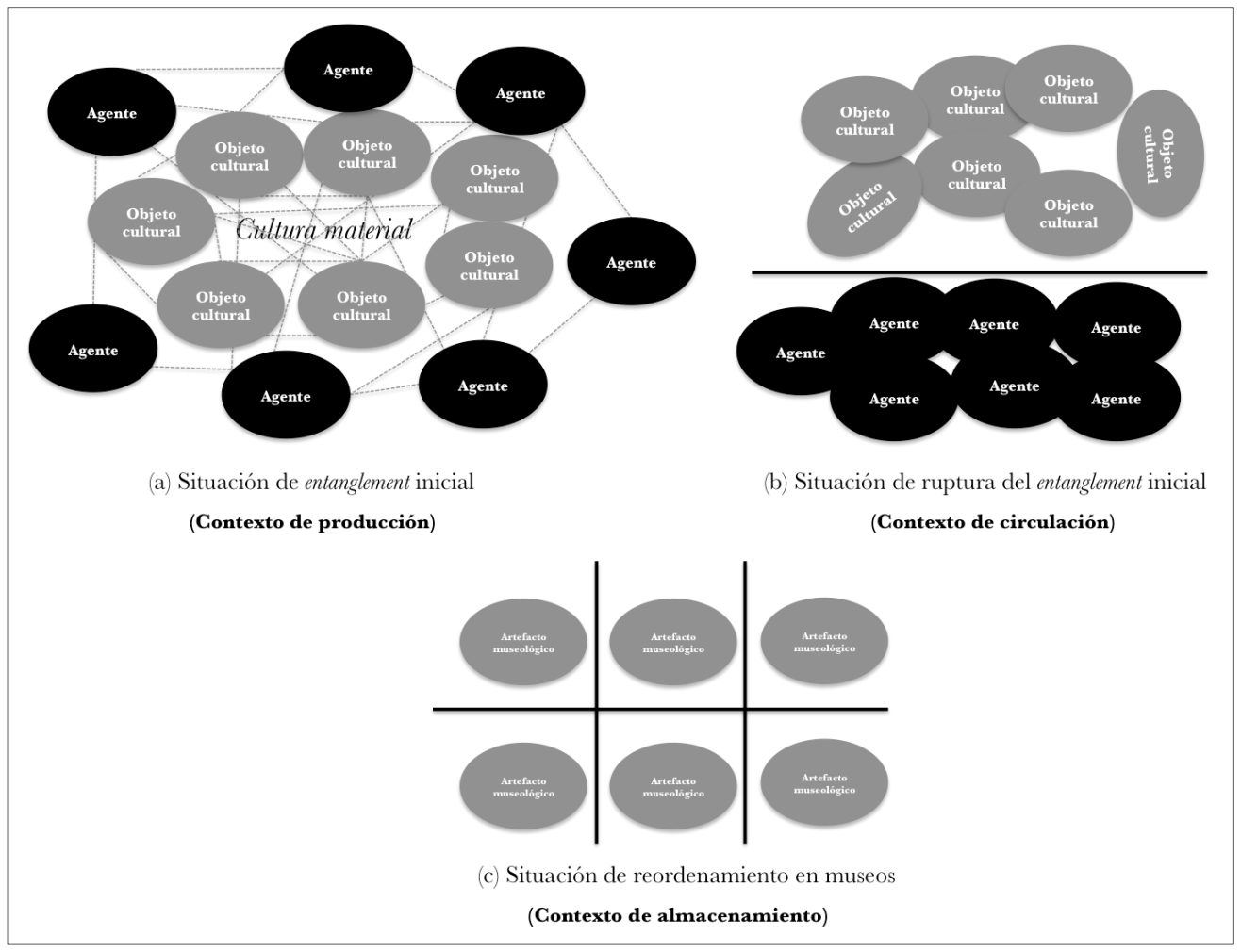

Figura 2 - La ruptura del entanglement inicial del contexto de los objetos culturales.

Tal como se muestra en la figura 2, la acción colonial, en tanto práctica predadora, constituyó una modalidad de reapropiación consciente tanto de los objetos culturales como de las micro- y macro-historias en las que se insertaban los mismos (a: Situación de entanglement inicial/ contexto de producción). Con ello, la ruptura del entanglement inicial operó a través de la separación que Occidente -o, mejor dicho, que la fuerza del cientificismo racionalista- había desplegado entre "sujeto" y "objeto" o, en otras palabras, entre "cosas" y "humanos" (b: Situación de ruptura del entanglement inicial/ contexto de circulación). ${ }^{94}$ Por otra parte, esta desarticulación entre cosas y humanos implicó la dispersión de la cultura material y el vaciado de significación de los objetos culturales en sus contextos primigenios. Finalmente, la lógica museológica se cimentó en el ocultamiento y olvido de las redes de significación inicial en las que se articulaban los objetos culturales, ahora ubicados de forma pasiva en las vitrinas de los diferentes establecimientos (c: Situación de reordenamiento en museos/ contexto de almacenamiento). 


\section{QUINTO PUNTO: EXOTIZAR ORIENTE Y CONSTRUIR SUDAMÉRICA A PARTIR DE LOS OBJETOS, LOS MUSEOS Y LAS HUMANIDADES}

Desde Latinoamérica, las metáforas sobre Oriente fueron múltiples y variadas. Por ejemplo, a mediados del siglo XIX, los libros de viajes, los artículos en periódicos o la literatura contribuyeron a su representación y descripción. Sin embargo, las producciones escritas y sus simbologías no fueron las únicas que pusieron en juego las ideas orientalistas. De hecho, son una de las tantas aristas de la formación y circulación de ideas e imaginarios. Al respecto, Edward Said puntualiza en las instituciones y sus actores sociales que se ven involucrados:

Todo escritor versado en Oriente (y esto es cierto incluso para Homero) asume algún precedente oriental, algún conocimiento previo de Oriente, al que se refiere y en el que se basa. Además, cada obra sobre Oriente se vincula con otras obras, con públicos, con instituciones, con el propio Oriente. El conjunto de relaciones entre obras, públicos y algunos aspectos particulares de Oriente constituye, por tanto, una formación analizable -por ejemplo, la de los estudios filológicos, de antologías de extractos de la literatura oriental, de libros de viaje, de fantasías orientales- cuya presencia en el tiempo, en el discurso, en las instituciones (escuelas, bibliotecas, servicios exteriores) le da fuerza y autoridad. ${ }^{95}$

A mediados del siglo XIX en Argentina, Domingo F. Sarmiento le dio forma a las interpretaciones orientalistas que delineaban una clara interpretación sociocultural: la antinomia "civilización y barbarie", en la cual África y América se encontraban del mismo lado de la matriz orientalista. ${ }^{96}$ Pero, para Sarmiento, no era toda América la atrasada, sino la de "los salvajes hijos del desierto", aquella determinada por la misma geografía del desierto. Pues, como afirma Martín Bergel, para Sarmiento y toda su generación, al mentar al Oriente, se estaba generando un otro del que no se consideraban parte, dado que ellos integraban una línea histórica que empujaba hacia el progreso y la civilización. ${ }^{97}$

La tesis orientalista ya había sido sugerida en los trabajos académicos de los pioneros de los estudios del pasado y la Filosofía de la Historia. Vicente Fidel López obtuvo el grado de Licenciado en Filosofía y Humanidades de la Universidad de Chile en 1845 con la lectura de la memoria sobre los resultados generales con que los pueblos antiguos habían contribuido a la civilización de la humanidad.

Además, con la preocupación de establecer el origen del "hombre" americano -lo que comenzaba a llamarse "americanismo"-, Vicente Fidel López proponía el estudio sobre la lengua de los incas siguiendo la tradición americanista francesa, la 
98. Cf. Schávelzon (2004). La traducción al francés del libro de Vicente Fidel López fue realizada por Gaston Maspero, cuando aún no se había convertido en un referente de la Egiptología occidental. El contrato establecía que el trabajo de este último consistía en traducir y revisar, no de criticar la postura del otro. Gaston Maspero escribió en reiteradas ocasiones artículos sobre temas precolombinos. Sobre su estadía en Montevideo (Uruguay) y el contexto cultural durante su visita, cf. Schávelzon (2004).

99. Moreno (1891, p. 50).

100. Ibid., p. 50. La Atlántida sería tema de análisis años después en uno de los capítulos del libro de Víctor Mercante, Tut-Ankh-Amon y la Civilización de Oriente, quien propuso, retomando a Florentino Ameghino, la imposibilidad de su existencia. Cf. Mercante (1928). cual hacía foco en los escritos como medio de construcción del conocimiento. La tesis de Vicente Fidel López, publicada en Las razas arias del Perú (1868), sostenía que la cultura andina era el resultado de la migración de pueblos prehelenos y griegos, lo que intentaba comprobar a partir de la Lingüística comparada..$^{98}$

Teniendo en cuenta el marco de discusión que señalamos en este apartado como en el anterior, haremos foco en dos instituciones diferentes pero con puntos en común: los Museos de La Plata y Etnográfico "Juan B. Ambrosetti" de Buenos Aires. Nos interesa plantear de qué manera ambas instituciones tomaron como modelo de ejecución y planeamiento las propuestas europeas, revalidando el despojo de Asia y África de sus objetos culturales, y, en simultáneo, participaron de la conformación del Estado nacional argentino.

\section{Museo de La Plata}

La tesis Vicente Fidel López era una propuesta de la existencia de vínculos entre los pueblos indígenas americanos y las sociedades antiguas europeas, entre ellas, la egipcia. Fue Francisco Pascasio Moreno, quien adhirió a esta idea, el que planteó la existencia de evidencia arqueológica para reafirmarla. Francisco P. Moreno consideraba que los "vidrios de colores", que se encontraron en Inglaterra y que eran atribuibles a los antiguos egipcios y los fenicios, "se les ha descubierto ya en Norte-América y el Museo de La Plata posee algunos hallados en nuestras provincias del Norte, en esta de Buenos Aires, y personalmente los he recogido en las necrópolis antiguas de Patagonia." ${ }^{99}$

De hecho, Francisco P. Moreno unas líneas más abajo, databa esos objetos en la Dinastía XVIII, según pudo comprobarlo en su visita a los museos franceses del Louvre y Lyon.

El encuentro entre el "hombre americano precolombino" con "sociedades antiguas europeas" era una idea alimentada por la hipótesis de la existencia de un continente perdido donde ambas identidades pudieron haber convivido. La Atlántida de Platón, para Francisco P. Moreno, podría ser una realidad: "y todo esto encamina a suponer que la famosa Atlántida de Platón, no fue otra cosa que América". ${ }^{100}$ La idea de que una sala del Museo de La Plata fomentara los estudios comparativos fue llevada adelante entre Francisco P. Moreno y Dardo Rocha.

En el año 1888, Dardo Rocha, tras algunas gestiones con el Museo de Boulaq en El Cairo, compró dos momias con sus ataúdes para el Museo de La 
Plata. Así se lo hacía saber a Francisco Moreno en dos cartas enviadas desde Egipto fechadas el 14 de marzo y 26 de julio de 1888 respectivamente:

[...] Creo que convendría hacer una sección de antigüedades egipcias que podría fomentarse y que serviría para estudios comparativos con las antigüedades americanas [...] Mucho me satisface su noticia que mi suposición sobre las relaciones entre los antiguos egipcios y los antiguos americanos parece comprobarse. Qué interesante y qué importante será establecer esto como una verdad científica y no debe perdonar esfuerzo para completar la sección que está formando. ${ }^{101}$

Este proyecto finalmente no se concretó. Sin embargo, las antigüedades egipcias encontraron su lugar entre las vitrinas del museo. ${ }^{102}$ En este sentido, un aporte sería realizado por Luis Ángel Viglione a finales del siglo XIX. En 1889, Luis Ángel Viglione realizó un viaje a Egipto y, en los talleres del Museo del Boulaq, adquirió calcos de importantes piezas egipcias. Lo más probable es que él mismo deseara realizar un aporte al proyecto del museo de calcos de Dardo Rocha, pero, a su muerte en 1890, las réplicas fueron donadas por su viuda al Museo de La Plata. Además, en el Museo de La Plata, creado en 1884 y abierto al público en 1888, era evidente que las sociedades antiguas orientales no pasaban desapercibidas al momento de conformar las colecciones para la institución, a partir del diseño mismo del edificio realizado por Francisco P. Moreno. La idea era un recorrido ascendente, a través de dos plantas espiraladas, representativo del proceso evolutivo. Como vimos, de acuerdo a Francisco P. Moreno, establecer una cronología de la sección del "hombre físico y moral" era un problema especialmente porque no consideraba resueltos los vínculos entre ambos continentes: "No se pueden examinar las inscripciones Hittitas de Dierablus, en el Occidente asiático sin pensar en los jeroglíficos mejicanos [... $]^{\prime \prime} .{ }^{103}$ Es decir, una sala egipcia tendría que tener lugar al finalizar este recorrido evolutivo. ${ }^{104}$ ¿Qué lugar ocuparon las sociedades antiguo-orientales? ¿Existió contacto con las americanas? ¿Cómo se presentaban estas complejas cronologías en las vitrinas del museo?

\section{Museo Etnográfico "Juan B. Ambrosetti" de Buenos Aires}

En cuanto al derrotero de las colecciones de piezas museológicas orientales, principalmente de origen egipcio, hoy en el Museo Etnográfico "Juan B. Ambrosetti" de Buenos Aires, se entrecruza la conformación histórico-institucional del actual Museo Argentino de Ciencias Naturales "Bernardino Rivadavia" (MACN). En un
101. Citado en Daneri (1980, p. 18-119).

102. En la actualidad, la sala egipcia del Museo de La Plata se completa con las piezas traídas por Abraham Rosenvasser, luego de un trabajo de cooperación francesa, a fines de la década del sesenta. En esa ocasión, un equipo de trabajo franco-argentino -en el que participó Abraham Ronsevasser-acudió al pedido de la UNESCO para salvaguardar los sitios arqueológicos que quedarían inundados con la construcción de la represa de Asuán.

103. Moreno, op. cit., p. 50.

104. Para las colecciones egipcias en el Museo de La Plata, cf. Daneri $(1978,1980)$. 
105. Cf. Castello (2014).

106. Ibid.

107. Ibid.

108. La colección egipcia del Museo Etnográfico de Buenos Aires fue publicada por primera vez en la Revista del Instituto de Historia Antigua Oriental por Abraham Rosenvasser y Perla Fuscaldo en tres de sus volúmenes. Rosenvasser (1972); Fuscaldo (1972, 1973, 1980). Anteriormente, Abraham Rosenvasser había sacado a la luz en el Journal of Egyptian Archaeology una copia y una fotografía de un papiro -conocido como "Papiro Buenos Aires"-, el cual contenía un fragmento del Cuento de Sinubé, en ese momento en el MACN. Al respecto, Rosenvasser (1934). Por otra parte, existe un trabajo sobre las piezas egipcias del Museo Etnográfico, en el que se hace foco en las figurinas de la colección. A propósito, cf. Iamarino, Lovecky y Neira Cordero (2016). Sobre el sarcófago de Amenirdis, cf. Bonanno (2018, 2019).

109. A propósito, sobre la conformación del acervo cultural del Museo Etnográfico de Buenos Aires, cf. Pegoraro (2009).

110. En relación con este punto, resultan interesantes los datos que encontramos entre los años 1908 y 1914 en cuanto a la adquisición de piezas provenientes de África, Asia y Oceanía: 1908: 167 piezas procedentes de Asia; 1909: 70 piezas procedentes de Oceanía; 1910: 270 piezas procedentes de África y 289 de Oceanía; 1911: 105 piezas procedentes de África y 273 de Oceanía; 1912: 107 piezas provenientes de Oceanía; 1913: 317 piezas procedentes de África, 353 de Asia y 335 de Oceanía; 1914: 91 piezas procedentes de África. Todos los datos en Pegoraro, op. cit. documento con fecha del 17 de agosto de 1812, Bernardino Rivadavia establecía la necesidad de disponer de un "Museo de Historia Natural", pero recién un decreto del 31 de diciembre de 1823 poseía el encabezado de "Museo Público" con el objetivo de llevar a cabo la instalación del establecimiento. 105

Las denominaciones del MACN cambiaron en un marco temporal de tres décadas, desde "Sala de física y de química, y de la conservación de los objetos de la Historia natural" (en el año 1826), hasta que finalmente Antonio Demarchi lo \|lamó en sus escritos "Museo de Historia Natural" (21-1 1-1 842/1 8-8-52). ${ }^{106}$ Luego del segundo gobierno de Juan Manuel de Rosas en 1852, pasó a denominarse "Museo Público de Buenos Aires" y se trasladó de los altos del Convento de Santo Domingo al edificio de la Manzana de las Luces. Hasta 1923, conservó como nombre "Museo Nacional de Historia Natural de Buenos Aires" y, a partir de ahí, "Museo Nacional de Historia Natural Bernardino Rivadavia", cuya nominación se cambió por la que lleva actualmente en 1948 y se reubicó en 1933 en su locación final en el Parque Centenario. ${ }^{107}$

En paralelo al cambio de nombre y el traslado de locación, dada la heterogénea colección de piezas que tenía el MACN, fueron desprendiéndose de estas y se dio origen a otros museos de Buenos Aires. Así, desde 1947, el Poder Ejecutivo decreta el traslado de tres de las secciones que componían la colección al Museo Etnográfico.

Desde ese momento, este último resguardó las piezas egipcias provenientes de diversos donantes que databan de la época de la Confederación Rosista en adelante. Sin embargo, no puede precisarse hasta el día de hoy la procedencia original de la mayoría de los objetos, otorgándole un carácter heterogéneo a la colección. Entre las piezas, se encuentran fragmentos del papiro de Khonsu-Thot y el Cuento de Sinuhé, el ataúd de Amenirdis, shabtis, un par de momias de animales y diversas estatuillas. ${ }^{108}$

En el caso del Museo Etnográfico, dependiente de la Facultad de Filosofía y Letras de la Universidad de Buenos Aires, cuya fundación se dio en 1904 de la mano de Juan Bautista Ambrosetti, profesor en la misma casa de estudios y encargado de los primeros trabajos de campo en la provincia de Salta por parte de la institución. ${ }^{109}$ El impulso que movilizó a Juan Bautista Ambrosetti fue doble: por un lado, académico y, por otro, coleccionista, siguiendo las modas imperantes del momento. Ese ímpetu coleccionista $y$, por consiguiente, propagador de las metáforas coloniales, se reprodujo en la organización de las exhibiciones del museo. De manera amplia, el museo participaba de la circulación de objetos culturales que eran el resultado del expolio de los países de Asia, África y Oceanía, ${ }^{110}$ y, por consiguiente, era un reproductor material del despojo imperialista del momento. 
Asimismo, Juan Baustista Ambrosetti, por medio del ministro Juan M. Garro, le solicitó al cónsul en Calcuta, Florencio de Basaldúa, que le consiguiera "figuritas representando tipos de la India; una colección de objetos religiosos brahmanes y, otra de los Parsis, todo barato", "11 así como le encargaba réplicas y calcos al Museo de Berlín de las piezas que este albergaba. En todos los casos, además del interés coleccionista, también existía una visión pedagógica, dado que cada una de las salas y/o vitrinas del museo se pensaban a partir del lema "una sección como una enseñanza en sí misma". ${ }^{112}$

\section{PUNTO DE LLEGADA: EL ORIENTALISMO, LAS METÁFORAS POSCOLONIALES Y LA AGENCIA DE LOS OBJETOS}

Nuestro punto de llegada se presenta en un "estado de abierto", pero, aún así, es un tanto más esperanzador que la propuesta de varios especialistas en el marco de los ANE studies. Por un lado, los museos de los países imperialistas y, por emulación, los que se erigieron en Latinoamérica, en particular, en ciudades como Buenos Aires y La Plata, se levantaron como espacios civilizadores y reproductores de agencia colonialista. Las vitrinas de los museos de fines del siglo XIX y comienzos del XX, contenedoras de los ahora artefactos museológicos, se manifestaban como espejos de los pueblos colonizados y, además, en tanto pantalla de una historia inmóvil. ${ }^{113}$

De la misma manera que las piezas museológicas descontextualizadas se colocaban en las vitrinas de los museos, la historia de los vencidos quedaba congelada en esos compartimentos estancos, tal como ocurrió con los pueblos indígenas que fueron víctimas de un genocidio a manos de las nacientes naciones de Latinoamérica. A propósito, la mal llamada "Campaña al Desierto" en Argentina constituye un buen ejemplo de este tipo de prácticas. Detrás de la expansión territorial hacia la Patagonia, también se consolidaba un relato colonialista de civilización versus barbarie, en la que los vencidos y su legado cultural fueron exhibidos como botín de guerra en los museos locales y también por medio de la conformación de los denominados "zoológicos humanos". Estos últimos se presentaron como el estadio supremo del colonialismo, donde esas alteridades eran exhibidas no sólo con la idea de resaltar las diferencias culturales, sino, principalmente, para marcar una inferioridad que la misma academia avalaba.

A esa mirada claramente racista, se le emparentó otra que se sustentó en el exotismo de esas alteridades de Asia, África e, incluso, América, y todas las
111. Ibid., p. 246.

112. Ibid., p. 284 .

113. En un sentido semejante, Eric Wolf también realiza una crítica a esta concepción de la historia eurocéntrica y que ubica en una periferia discursiva y gnoseológica a todo saber considerado subalterno. De esta forma, se le niega la posibilidad de circulación a los discursos históricos por fuera de lo que plantea Occidente. Wolf (1982). 
prácticas culturales de dichos pueblos fueron pensadas al unísono desde una narrativa occidental, tal como ocurrió en el contexto de la Antropología del siglo XIX. No obstante, la Antropología -así como las demás Humanidades- pudo realizar un proceso de introspección disciplinar y cuestionar las ideas que se defendían en un comienzo con una fuerte impronta eurocéntrica. No sucedió lo mismo ni con la Egiptología ni la Asiriología, las cuales, en buena medida, siguieron ancladas en una tradición filológica y, a su vez, sobre todo la primera, sustentada por ciertas prácticas basadas en el asombro y fascinación que despertaban los mismos objetos culturales que salían de las excavaciones arqueológicas.

Pero, ¿qué hacer ante las metáforas coloniales que derivaron, en buena medida, en la búsqueda del "buen salvaje", en la "caza del tesoro" y en modas culturales como la egiptomanía? La respuesta no es en absoluto confusa. En principio, se requiere de la vigilancia epistemológica constante de los miembros de la comunidad científica y, en especial, de egiptólogos y asiriólogos, quienes deberían no mostrarse como chamanes sino más bien como los encargados de desexotizar o, mejor aún, exorcizar los objetos de las miradas colonialistas y/o fanáticas. En relación a este último punto, opera una cuestión intrasubjetiva, de la que muchos académicos lamentablemente también son víctimas: tanto la mirada colonialista como la de un fanático es moralizante y, por consiguiente, hay una construcción preconcebida sobre lo que se espera ver y/o encontrar y, además, hay poca tolerancia al cambio. En ese sentido, se (re-)produce, de manera clara, una visión anclada en un paraíso que parece que Oriente lo expresa y/o contiene. La moral eurocéntrica -o más bien occidental- necesita de una alteridad colonizada que le asegure su lugar hegemónico y, por ello, la inmoviliza y condena a la no-historia. A pesar de ello, los movimientos intelectuales subalternos han sacado del letargo a los pueblos considerados sin historia y, con ello, se han propuesto la (re-)construcción de las memorias nativas, las cuales, sin desconocer la "herida colonial", son operadas por sujetos activos y conscientes de su propio pasado. Como contracara, la reacción conservadora de la posición moral occidental busca restringir la capacidad de acción de estos grupos, estableciendo cuáles son los parámetros de cientificidad o racionalidad aceptados para los procesos de resemantización y escritura de las historias locales.

En segundo lugar, ante este enfoque moralizante y conservador, es saludable y necesario una perspectiva poscolonial que reconvierta los artefactos museológicos en objetos culturales en sus propios contextos de producción y circulación, al tiempo que invite y (re-)integre a la Egiptología y la Asiriología a las corrientes interdisciplinarias que hoy priman en el ámbito de las Ciencias Humanas.

Además de devolver los objetos culturales a sus propias tramas contextuales iniciales y, en efecto, de significación primaria, también es imperiosamente ineludible 
el estudio y manejo de los sistemas de escritura antiguos y, a través de ellos, de las lenguas que por medio de los mismos se materializaban. Si bien los sistemas de escritura antiguos -como el jeroglífico para escribir el egipcio y el cuneiforme para el sumerio, el acadio y/o el hitita- eran manejados por una elite intelectual que hegemonizaba dichos procesos de transmisión cultural, es una aproximación necesaria en la deconstrucción de la historia de todas las sociedades de Asia y África. No obstante, consideramos también oportuno el planteo de Walter Ong sobre una "memoria oral" con un fuerte componente somático frente a una "memoria textual", donde predomina un componente verbal extracorpóreo. ${ }^{114}$ Así, oralidad/ escritura constituyen dos lógicas de transmisión del conocimiento que, en estudios recientes, no se las presenta como dos instancias en lo absoluto irreconciliables. De este manera, las memorias nativas surgidas del giro poscolonial se enfrentan al complejo proceso de re-contextualización de sus propios objetos culturales y las historias locales en las que ellos se insertan, reconciliando tanto la memoria oral con la propiamente textual y, además, repensando los parámetros cientificistas/ racionalistas eurocéntricos. Con ello, el proceso de revisión y reescritura del pasado no sólo es una acción científica, sino también una acción necesariamente política.

Por tal motivo, el foco puesto en los objetos y, en particular, considerando el habitus material ${ }^{115}$ de los mismos, permite rescatarlos del entrampamiento pasivo en los que las metáforas coloniales los ubicaron. Por ello, así como Gayatri Chakravorty Spivak se preguntaba si el sujeto subalterno podía hablar, ${ }^{116}$ es importante considerar, desde una mirada poscolonial, la agencia de los objetos culturales, ${ }^{117}$ la cual habita a pesar de la visión moralizante de las vitrinas de los museos y los fanáticos.

\section{AGRADECIMIENTOS}

Queremos agradecer, por un lado, las sugerencias y los comentarios efectuados por las/os evaluadoras/es anónimas/os, los cuales tanto por su carácter afable como comprometido en la lectura atenta del manuscrito inicial han enriquecido enormemente la producción final del mismo. Por otro lado, estamos en deuda con la lectura genuina y generosa de Anita Fattori (Universidade de São Paulo) del artículo primigenio. Asimismo, agradecemos a María Laura lamarino (IMHICHU, CONICET/ Universidad de Buenos Aires) por la lectura primaria del trabajo y el envío del paper inédito de su autoría sobre las piezas egipcias del Museo Etnográfico de Buenos Aires. No obstante, cualquier error corre bajo nuestra absoluta y expresa responsabilidad. Este trabajo se encuentra financiado por los siguientes proyectos de 
investigación: PIP/CONICET (GI $11220170100966 C O$ ): "Arqueología de espacios funerarios: epigrafía y cultura material en el Cercano Oriente Antiguo" (Directora: Dra. Liliana M. Manzi); Proyecto UBACyT (Modalidad 1/ $\mathrm{N}^{\circ}$ $20020170100688 B A)$ :" Registros funerarios en el Cercano Oriente Antiguo: análisis de estructuras, representaciones e inscripciones" (Directora: Dra. Liliana M. Manzi); PID/UNLP (H930): "Conservación y estudio de la tumba de Amenmose, TT3 18 en Sheikh Abd el-Qurna, Luxor, Egipto" (Directora: Dra. Andrea Zingarelli) y PPID/UNLP (80120190500068LP): "La materialidad de la escritura: los textos para la construcción de la memoria en el Mediterráneo antiguo" (Directora: Dra. Leila Salem). 


\title{
REFERENCIAS
}

\author{
LIBROS, ARTÍCULOS Y TESIS
}

ABRAHAMI, Philippe. La sumérologie à ses débuts: du déchiffrement à la grammaire d'A. Poebel (1852-1923). Egypte, Afrique E Orient, Montségur, v. 47, p. 27-36, 2007.

ABT, Jeffrey. American Egyptologist: the life of James Henry Breasted and the creation of his Oriental Institute. Chicago: University of Chicago Press, 2011.

ABUSCH, Tzvi et al. (eds.). Historiography in the cuneiform world. Bethesda: CDL, 2001. Part 1.

APPADURAI, Arjun. Introduction: commodities and the politics of value. In: The social life of things: commodities in cultural perspective. Cambridge: Cambridge University Press, 1986. p. 3-63.

ASSMANN, Jan. Egyptian mysteries and secret societies in the age of Enlightenment. A 'mnemohistorical' study. Aegyptiaca, Heidelberg, n. 1, p. 4-25, 2017. Doi: <https://doi.org/10.11588/ aegyp.2017.1.40162>.

ASSMANN, Jan. El lugar de Egipto en la historia de la memoria de Occidente. In: SCHRÖDER, Gerhart; BREUNINGER, Helga (comps.). Teoría de la cultura. Ciudad de México: Fondo de Cultura Económica, 2005. p. 54-74.

ASSMANN, Jan. Religio duplex: how the Enlightenment reinvented Egyptian religion. Cambridge: Polity Press, 2014.

BAGG, Ariel M. Geschichtsschreibung in der Assyriologie: Überlegungen zu W. Mayer, Politik und Kriegskunst der Assyrer. Die Welt des Orients, Göttingen, v. 29, p. 98-108, 1998.

BAHRANI, Zainab. Race and ethnicity in Mesopotamian antiquity. World Archaeology, London, v. 38, n. 1, p. 48-59, 2006.

BAHRANI, Zainab. The graven image: representation in Babylonia and Assyria. Philadelphia: University of Pennsylvania Press, 2003.

BASELLO, Gian Pietro. Elam between Assyriology and Iranian studies. In: PANAINO, Antonio; PIRAS, Andrea (eds.). Schools of Oriental Studies and the development of modern historiography. Milan: Università di Bologna \& Isiao, 2004. p. 1-40.

BERGEL, Martín. El Oriente desplazado: los intelectuales y los orígenes del tercermundismo en la Argentina. Bernal: Editorial de la Universidad Nacional de Quilmes, 2015. 
BERNAL, Martin. Black Athena: the Afroasiatic roots of classical civilization: volume II: the archaeological and documentary evidence. New Brunswick: Rutgers University Press Classics, 1987.

BERNAL, Martin. Black Athena: the Afroasiatic roots of classical civilization: volume III: The linguistic evidence. New Brunswick: Rutgers University Press Classics, 2006.

BERNAL, Martin. Black Athena writes back: Martin Bernal responds to his critics. Durham: Duke University Press, 2001.

BIERBRIER, Morris L. Who was who in Egyptology. London: Egypt Exploration Society, 2012.

BONANNO, Mariano. El sarcófago de Amenirdis (Inv. -28104-): apuntes en relación a su programa iconográfico y textual: sitio de procedencia, datación y depositación. Arqueología, Buenos Aires, v. 25, n. 1, p. 187-201, 2019. Doi: <https://doi.org/10.34096/arqueologia.t25. n1.6012>.

BONANNO, Mariano. Iconografía de la tapa del sarcófago de Amenirdis (Inv. -28104-). Mirada y agencia como herramientas de análisis. Hélade, Río de Janeiro, v. 4, n. 2, p. 29-42, 2018.

BOTTÉRO, Jean. Éloge d'une science inutile: l'orientalisme. Akkadica, Brussels, v. 30, p. 12-26, 1982.

CABRERA, Rodrigo. Entre cuñas, tablillas y escribas: la materialidad de los paisajes funerarios en Mesopotamia durante la tercera dinastía de Ur. Revista del Museo de Antropología, Córdoba, v. 12, n. 2, p. 7-22, 2019. Doi: <https://doi.org/10.31048/1852.4826.v12.n2.23526>.

CARDOSO, Ciro Flamarion Santana. A cidade-Estado antiga. São Paulo: Ática, 1987.

CARDOSO, Ciro Flamarion Santana. O Egito Antigo. São Paulo: Brasiliense, 1982.

CARRUTHERS, William (ed.). Histories of Egyptology: interdisciplinary measures. London: Routledge, 2014.

CARRUTHERS, William. The rise and fall of ancient Egypt? Egyptology's never-ending story. Antiquity, Cambridge, v. 85, n. 330, p. 1144-1447, 2011. Doi: <https://doi.org/10.1017/ S0003598X00062165>.

CASTEllo, Hugo. Historia del Museo Público de Buenos Aires (1812-1884). Cuadernos manzana de las luces-crónicas de su historia, Buenos Aires, n. 11, p. 1-30, 2014.

CHARPIN, Dominique. Renan, un sémitisant au berceau de l'Assyriologie. In: LAURENS, Henry (ed.). Ernest Renan: la science, la religion, la République. Paris: Odile Jacob, 2013. p. 77-99. 
COLLA, Elliot. Conflicted antiquities: Egyptology, Egyptomania, Egyptian modernity. Durham: Duke University Press, 2007.

COOPER, Jerrold. Posing the Sumerian question: race and scholarship in the early history of Assyriology. In: MICHALOWSKI, Piotr et al. (eds.). Velles paraules: Ancient Near Eastern Studies in honor of Miguel Civil on the occasion of his sixty-fifth birthday. Barcelona: Ausa, 1991. p. 47-66.

CÓRDOBA ZOILO, Joaquín María; JIMÉNEZ ZAMUDIO, Rafael; SEVILLA CUEVA, Covadonga (eds.). El redescubrimiento de Oriente Próximo y Egipto: viajes, hallazgos e investigaciones: actas del Primer Seminario Monográfico de Primavera. Madrid: Universidad Autónoma de Madrid, 2001.

CÓRDOBA ZOILO, Joaquín María; PÉREZ DÍE, María del Carmen (eds.). La aventura española en Oriente (1166-2006): la arqueología española en Oriente: nacimiento y desarrollo de una nueva ciencia. Madrid: Ministerio de Cultura, 2006a.

CÓRDOBA ZOILO, Joaquín María; PÉREZ DÍE, María del Carmen (eds.). La aventura española en Oriente (1166-2006): viajeros, museos y estudiosos en la historia del redescubrimiento del Oriente próximo antiguo. Madrid: Ministerio de Cultura, 2006b.

DA RIVA, Rocío; VIDAL, Jordi (eds.). Descubriendo el antiguo Oriente: pioneros y arqueólogos de Mesopotamia y Egipto a fines del s. XIX y principios del s. XX. Barcelona: Bellaterra, 2015.

DANERI, Alicia. Las piezas egipcias del Museo de Ciencias Naturales de La Plata (Primera parte). Revista del Instituto de Historia Antigua Oriental, Buenos Aires, v. 4, p. 129-134, 1978.

DANERI, Alicia. Las piezas egipcias del Museo de Ciencias Naturales de La Plata (Segunda parte). Revista del Instituto de Historia Antigua Oriental, Buenos Aires, v. 5, p. 117-139, 1980.

DAWSON, Warren Royal. Charles Wycliffe Goodwin, 1817-1878: a pioneer in Egyptology. Oxford: Oxford University Press, 1934.

DÉMARE-LAFONT, Sophie. L'Assyriologie est-elle une invention de l'Occident? Droit et Cultures, Paris, p. 105-116, 2008.

DUSSEL, Enrique. Europa, modernidad y eurocentrismo. In: LANDER, Edgardo (comp.). $L a$ colonialidad del saber: eurocentrismo y ciencias sociales: perspectivas latinoamericanas. Buenos Aires: Consejo Latinoamericano de Ciencias Sociales, 2004. p. 39-51.

EATON, Anne Wescott. Artifacts and their functions. In: GASKELL, Ivan; CARTER, Sarah Anne (eds.). The Oxford handbook of History and material culture. Oxford: Oxford University Press, 2020. p. 35-53.

FALES, Frederick Mario. L'historien du Proche-Orient antique: entre passé et présent. Transeuphratène, Paris, v. 31, p. 55-66, 2006. 
FINKELSTEIN, Jacob Joel. Mesopotamian historiography. Proceedings of the American Philosophical Society, Philadelphia, v. 107, n. 6, p. 461-472, 1963.

FRITZE, Ronald. Egyptomania: a history of fascination, obsession and fantasy. London: Reaktion Books, 2016.

FUSCALDO, Perla. Las piezas egipcias del Museo Etnográfico de Buenos Aires (Primera parte). Revista del Instituto de Historia Antigua Oriental, Buenos Aires, v. 1, p. 57-97, 1972.

FUSCALDO, Perla. Las piezas egipcias del Museo Etnográfico de Buenos Aires (Segunda parte). Revista del Instituto de Historia Antigua Oriental, Buenos Aires, v. 2, p. 139-166, 1973.

FUSCALDO, Perla. Las piezas egipcias del Museo Etnográfico de Buenos Aires (Última parte). Revista del Instituto de Historia Antigua Oriental, Buenos Aires, v. 4, p. 87-97, 1980.

GANGE, David. Dialogues with the dead: Egyptology in British culture and religion, 1822-1922. Oxford: Oxford University Press, 2013.

GASQUET, Axel. Oriente al sur: el orientalismo literario argentino de Esteban Echeverría a Roberto Arlt. Buenos Aires: Eudeba, 2010.

GELL, Alfred. Art and agency: an anthropological theory. Oxford: Oxford University Press, 1998.

GOOCH, George Peabody. History and historians in the nineteenth century. London: Longmans, Green, and Co., 1913.

GOSDEN, Chris; MARSHALL, Yvonne. The cultural biography of objects. World Archaeology, London, v. 31, n. 2, p. 169-178, 1999.

HARTOG, François. Le miroir d'Hérodote: essai sur la représentation de l'autre. Paris: Gallimard, 1980.

HICKS, Dan. The material-cultural turn: event and effect. In: HICKS, Dan; BEAUDRY, Mary Carolyn (eds.). The Oxford handbook of material culture studies. Oxford: Oxford University Press, 2010. p. 25-98.

HOBSBAWM, Eric. La era del imperio, 1875-1914. Barcelona: Crítica, 2007.

HODDER, Ian. Human-thing entanglement: towards an integrated archaeological perspective. Journal of the Royal Anthropological Institute, London, v. 17, n. 1, p. 154-177, 2011.

HOOCK, Holger. The British state and the Anglo-French wars over antiquities, 1798-1858. The Historical Journal, Cambridge, v. 50, n. 1, p. 49-72, 2007. 
IAMARINO, María Laura; LOVECKY, Gabriela; NEIRA CORDERO, Elisa. El ajuar funerario y la memoria cultural: las piezas egipcias del Museo Etnográfico de Buenos Aires. In: II $^{\mathrm{a}}$ Conferencia de Egiptología Latinoamericana, septiembre de 2016. Buenos Aires: Instituto de Historia Antigua Oriental, Universidad de Buenos Aires, 2016. p. 1-20.

JAMES, Thomas Garnet Henry. Howard Carter: the path to Tutankhamun. London: Tauris-Parke Paperbacks, 2001.

KRAMER, Samuel Noah. From the tablets of Sumer: twenty-five firsts in man's recorded History. Indian Hills: Falcon's Wing Press, 1956.

KRISTEVA, Julia. Pouvoirs de l’horreur essai sur l'abjection. Paris: Éditions du Seuil, 1980.

LAKOFF, Geoger; JOHNSON, Mark. Metaphors we live by. Chicago: University of Chicago Press, 1980.

LEFKOWITZ, Mary. Not out of Africa: how afrocentrism became an excuse to teach myth as History. New York: A New Republic of Books, 1996.

LIVERANI, Mario. Immaginare Babele: due secoli di studi sulla città orientale antica. Roma: Gius. Laterza \& Figli, 2013.

MACDONALD, Sally; RICE, Michel (eds.). Consuming ancient Egypt. Walnut Creek: Lef Coast Press, Inc., 2009.

MARCHAND, Suzanne. German orientalism in the age of empire: religion, race, and scholarship. Cambridge: Cambridge University Press, 2009.

MARCHAND, Suzanne; GRAFTON, Anthony. Martin Bernal and his critics. Arion: a Journal of Humanities and the Classics, Boston, v. 5, n. 2, p. 1-35, 1997.

MERCANTE, Víctor. Tut-ankh-amon y la civilización de Oriente. Buenos Aires: García Santos, 1928.

MESKELL, Lynn. Introduction: object orientations. In: Archaeologies of materiality. Malden: Blackwell Publishing, 2005. p. 1-17.

MESKELL, Lynn. The practice and politics of Archaeology in Egypt. The New York Academy of Sciences, New York, v. 925, n. 1, p. 146-169, 2020. Doi: <https://doi.org/10.1111/j.1749-6632.2000. tb05588.x>.

MIGNOLO, Walter. La colonialidad a lo largo y a lo ancho: el hemisferio occidental en el horizonte colonial de la modernidad. In: LANDER, Edgardo (comp.). La colonialidad del saber: eurocentrismo y ciencias sociales: perspectivas latinoamericanas. Buenos Aires: Consejo Latinoamericano de Ciencias Sociales, 2004. p. 52-82. 
MILLER, Daniel (ed.). Material cultures: why some things matter. London: University College London Press, 1998.

MILLER, Daniel. Material culture and mass consumption. Malden: Blackwell Publishing, 1987.

MILLER, Daniel. Materiality: an introduction. In: Materiality. Durham: Duke University Press, 2005. p. $1-50$.

MITCHELL, Timothy. Colonising Egypt. Berkeley: University of California Press, 1991.

MOLINA, Manuel. Ur, ciudad de los caldeos: Sir Leonard Woolley en la residencia de estudiantes. In: DIEGO, Estrella de; GARCÍA-VELASCO, José (eds.). Viajeros por el conocimiento. Madrid: Residencia de Estudiantes, 2010. p. 521-569.

MORENO, Francisco. El museo de La Plata: rápida ojeada sobre su fundación y desarrollo. Revista del Museo, La Plata, v. 1, p. 28-55, 1891.

MORENO GARCÍA, Juan Carlos. The cursed discipline? The peculiarities of Egyptology at the turn of the twenty-first century. In: CARRUTHERS, William (ed.). Histories of Egyptology: interdisciplinary measures. London: Routledge, 2014. p. 50-63.

MORENO GARCÍA, Juan Carlos. Un mito tenaz: el Egipto antiguo o el paraíso perdido en la obra de los egiptólogos de finales del siglo XIX y comienzos del siglo XX. In: DA RIVA, Rocío; VIDAL, Jordi (eds.). Descubriendo el Antiguo Oriente: pioneros y arqueólogos de Mesopotamia y Egipto a fines del s. XIX y principios del s. XX. Barcelona: Bellaterra, 2015. p. 103-122.

MOSER, Stephanie. Wondrous curiosities: ancient Egypt at the British museum. Chicago: University of Chicago Press, 2006.

NYORD, Rune (ed.). Concepts in Middle Kingdom funerary culture: proceedings of the Lady Wallis Budge Anniversary Symposium held at Christ's College, Cambridge, 22nd January 2016. Leiden: Brill, 2019.

ONG, Walter. Orality and literacy: the technologizing of the word. London: Routledge, 1982.

OPPENHEIM, Adolf Leo. Assyriology: why and how? Current Anthropology, Chicago, v. 1, n. 5-6, p. 409-423, 1960.

PARRAMORE, Lynn. Reading the Sphinx: Ancient Egypt in nineteenth-century literary culture. New York: Palgrave Macmillan, 2008.

PEGORARO, Andrea. Las colecciones del Museo Etnográfico de la Universidad de Buenos Aires: un episodio en la historia del americanismo en la Argentina 1890-1927. 2009. Disertación (Doctorado en Arqueología) - Facultad de Filosofía y Letras, Universidad de Buenos Aires, Buenos Aires, 2009. 
PEREYRA, Violeta; ZINGARELLI, Andrea. Una interpretación del tributo en el Egipto Imperial. Anales de Historia Antigua, Medieval y Moderna, Buenos Aires, v. 35-36, p. 81-96, 2003.

PETRIE, William Matthew Flinders. Methods and aims in Archaeology. London: MacMillan and Co., 1904.

PODGORNY, Irina. William Flinders Petrie: un repositorio nacional para la ciencia y el arte. Bogotá: Universidad Nacional de Colombia, 2011.

POZZER, Katia Maria Paim. Guerra, violência e memória cultural nas imagens assírias. Anos 90, Porto Alegre, v. 25, n. 47, p. 39-59, 2018. Doi: <http://dx.doi.org/10.22456/1983201X.80830>.

QUIJANO, Aníbal. Colonialidad del poder, eurocentrismo y América Latina. In: LANDER, Edgardo (comp.). La colonialidad del saber: eurocentrismo y ciencias sociales: perspectivas latinoamericanas. Buenos Aires: Consejo Latinoamericano de Ciencias Sociales, 2004. p. 193-238.

RAY, John. The Rosetta Stone and the rebirth of ancient Egypt. London: Profile Books, 2008.

REDE, Marcelo. Estudos de cultura material: uma vertente francesa. Anais do Museu Paulista, São Paulo, v. 8, n. 1, p. 281-291, 2001.

REDE, Marcelo. Família e patrimônio fundiário: notas para o estudo da economia doméstica na antiga Mesopotâmia. História e Economia, Lisboa, v. 3, n. 1, p. 71-102, 2007a.

REDE, Marcelo. Família e patrimônio na antiga Mesopotâmia. Rio de Janeiro: Mauad X, 2007b.

REDE, Marcelo. História a partir das coisas: tendências recentes nos estudos de cultura material. Anais do Museu Paulista, São Paulo, v. 4, n. 1, p. 265-282, 1996.

REDE, Marcelo. Materiality and History: some reflections. In: MAYNART, Érika; VELLOZA, Carolina; LEMOS, Rennan (eds.). Perspectives on materiality in ancient Egypt: agency, cultural reproduction and change. Oxford: Archaeopress Publishing, 2018. p. 74-86.

REID, Donald Malcolm. Contesting antiquity in Egypt: archaeologies, museums, and the struggle for identities from World War I to Nasser. Cairo: The American University in Cairo Press, 2016.

REID, Donald Malcolm. Indigenous Egyptology: the decolonization of a profession? Journal of the American Oriental Society, New Haven, v. 105, n. 2, p. 233-246, 1985.

REID, Donald Malcolm. Whose pharaohs? Archaeology, museums and Egyptian national identity from Napoleon to World War I. Berkeley: University of California Press, 2002. 
RICHARDS, Janet. Society and death in Ancient Egypt: mortuary landscapes of the Middle Kingdom. Ann Arbor: University of Michigan, 2009.

RICHARDSON, Seth. Mesopotamian political History: the perversities. Journal of Ancient Near Eastern History, Bellingham, v. 1, n. 1, p. 61-93, 2014. Doi: <https://doi.org/10.1515/ janeh-2013-0005>.

RIGGS, Christina. Ancient Egypt in the museum: concepts and constructions. In: LLOYD, Alan B. (ed.). A companion to ancient Egypt: volume I. Oxford: Wiley-Blackwell, 2010. p. 1129-1153.

ROBB, John. Material time. In: GASKELL, Ivan; CARTER, Sarah Anne (eds.). The Oxford handbook of History and material culture. Oxford: Oxford University Press, 2020. p. 124-139.

ROBB, John. What do things want? object design as a middle range theory of material culture. Archeological Papers of the American Anthropological Association, Arlington, v. 26, p. 166-180, 2015. Doi: <https://doi.org/10.1111/apaa.12069>.

ROSENVASSER, Abraham. A new duplicate text of the Story of Sinuhe. Journal of Egyptian Archaeology, London, v. 20, n. 1/2, p. 47-50, 1934

ROSENVASSER, Abraham. Las piezas egipcias del Museo Etnográfico de Buenos Aires (Primera parte). Revista del Instituto de Historia Antigua Oriental, Buenos Aires, v. 1, p. 4-57, 1972.

SAID, Edward. Orientalism. New York: Pantheon, 1978.

SALEM, Leila. El orientalismo en tensión: lecturas sobre Egipto en los relatos de viaje a finales del siglo XIX en Argentina. Revista de Historia Americana y Argentina, Mendoza, v. 53, p. 39-81, 2018.

SCHÁVELZON, Daniel. The South American connection Gaston Maspero, Egyptology and Americanist Archaeology at Montevideo (Uruguay), 1868. Bulletin of the History of Archaeology, London, v. 14, n. 1, p. 15-24, 2004. Doi: <http://doi.org/10.5334/bha.14103>.

SMITH, Stuart Tyson. Askut in Nubia: the economics and ideology of Egyptian imperialism in the second millennium BC. London: Kegan Paul International, 1995.

SMITH, Stuart Tyson. Wretched Kush: ethnic identities and boundries in Egypt's Nubian Empire. New York: Routledge, 2003.

SCHMITZ, Thomas A. Ex Africa lux? Black Athena and the debate about Afrocentrism in the US. Göttinger Forum für Altertumswissenschaft, v. 2, p. 17-76, 1999.

SPIVAK, Gayatri Chakravorty. Can the subaltern speak? In: NELSON, Cary; GROSSBERG, Lawrence (eds.). Marxism and the interpretation of culture. London: Macmillan, 1988. p. 271-313. 
STARKEY, Paul; STARKEY, Janet (eds.). Travellers in Egypt. London: I. B. Tauris, 1998.

STEVENSON, Alice. Egyptian Archaeology and the museum. In: GODSEN, Chris (ed.). Oxford handbooks online. Oxford: Oxford University Press, 2015. p. 1-15.

STEVENSON, Alice. Scattered finds: Archaeology, Egyptology and museums. London: UCL Press, 2019.

TATOMIR, Renata. Egyptomania in antiquity and modern world literature: imaginary, intercultural context and mentality. Discourse as a Form of Multiculturalism in Literature and Communication, Tîrgu-Mures, v. 3, p. 566-581, 2015.

THOMPSON, Jason. Wonderful things: a History of Egyptology: 1: from antiquity to 1881. Cairo: American University in Cairo, 2015.

THOMPSON, Jason. Wonderful things: a History of Egyptology: 2: the Golden Age: 1881-1914. Cairo: American University in Cairo, 2016.

THOMPSON, Jason. Wonderful things: a History of Egyptology: 3: from 1914 to the twenty-first century. Cairo: American University in Cairo, 2018.

UCKO, Peter; CHAMPION, Timothy (eds.). Wisdom of ancient Egypt: changing visions through the ages. London: University College London Press, 2003.

VAN DE MIEROOP, Marc. Cuneiform texts and the writing of History. London: Routledge, 1999.

VERDEVOYE, Paul. Viajes por Francia y Argelia. In: SARMIENTO, Domingo Faustino. Viajes por Europa, África y América (1845-1847) y diario de gastos. Buenos Aires: Colección Archivos, 1993. p. 639-715.

VIDAL, Jordi. Reflexiones historiográficas sobre el orientalismo antiguo. In: DA RIVA, Rocío; VIDAL, Jordi (eds.). Descubriendo el antiguo Oriente: pioneros y arqueólogos de Mesopotamia y Egipto a fines del s. XIX y principios del s. XX. Barcelona: Bellaterra, 2015. p. 25-36.

VITA, Juan Pablo. La asiriología según los asiriólogos. Cadmo, Lisboa, v. 22, p. 9-18, 2012.

WESTENHOLZ, Aage. Does Assyriology have a future? Kaskal, Firenze, v. 3, p. 275-283, 2006.

WILSON, John Albert. Signs and wonders upon Pharaob: a History of American Egyptology. Chicago: University of Chicago Press, 1964.

WOLF, Eric. Europe and the people without History. Berkeley: University of California Press, 1982. 
WORTHAM, John David. British Egyptology, 1549-1906. Newton Abbot: David and Charles, 1971.

ZINGARELLI, Andrea. Asiatic mode of production: considerations on ancient Egypt. In: GRACA, Laura da; ZINGARELLI, Andrea (eds.). Studies on pre-capitalist modes of production. Leiden: Brill, 2015. p. 27-76.

Artículo presentado el: 26/09/2020. Aprobado: 12/04/2021.

\section{(c) BY}

All the contents of this journal, except where otherwise noted, is licensed under a Creative Commons Attribution License 